\title{
New cloud chamber experiments on the heterogeneous ice nucleation ability of oxalic acid in the immersion mode
}

\author{
R. Wagner, O. Möhler, H. Saathoff, M. Schnaiter, and T. Leisner \\ Karlsruhe Institute of Technology, Institute for Meteorology and Climate Research, Karlsruhe, Germany \\ Received: 17 November 2010 - Published in Atmos. Chem. Phys. Discuss.: 2 December 2010 \\ Revised: 23 February 2011 - Accepted: 27 February 2011 - Published: 9 March 2011
}

\begin{abstract}
The heterogeneous ice nucleation ability of oxalic acid in the immersion mode has been investigated by controlled expansion cooling runs with airborne, ternary solution droplets composed of, (i), sodium chloride, oxalic acid, and water $\left(\mathrm{NaCl} / \mathrm{OA} / \mathrm{H}_{2} \mathrm{O}\right)$ and, (ii), sulphuric acid, oxalic acid, and water $\left(\mathrm{H}_{2} \mathrm{SO}_{4} / \mathrm{OA} / \mathrm{H}_{2} \mathrm{O}\right)$. Polydisperse aerosol populations with median diameters ranging from $0.5-0.7 \mu \mathrm{m}$ and varying solute concentrations were prepared. The expansion experiments were conducted in the AIDA aerosol and cloud chamber of the Karlsruhe Institute of Technology at initial temperatures of 244 and $235 \mathrm{~K}$. In the ternary $\mathrm{NaCl} / \mathrm{OA} / \mathrm{H}_{2} \mathrm{O}$ system, solid inclusions of oxalic acid, presumably nucleated as oxalic acid dihydrate, were formed by temporarily exposing the ternary solution droplets to a relative humidity below the efflorescence point of $\mathrm{NaCl}$. The matrix of the crystallised $\mathrm{NaCl}$ particulates triggered the precipitation of the organic crystals which later remained as solid inclusions in the solution droplets when the relative humidity was subsequently raised above the deliquescence point of $\mathrm{NaCl}$. The embedded oxalic acid crystals reduced the critical ice saturation ratio required for the homogeneous freezing of pure $\mathrm{NaCl} / \mathrm{H}_{2} \mathrm{O}$ solution droplets at a temperature of around $231 \mathrm{~K}$ from 1.38 to about 1.32. Aqueous solution droplets with OA inclusions larger than about $0.27 \mu \mathrm{m}$ in diameter efficiently nucleated ice by condensation freezing when they were activated to micron-sized cloud droplets at $241 \mathrm{~K}$, i.e., they froze well above the homogeneous freezing temperature of pure water droplets of about $237 \mathrm{~K}$. Our results on the immersion freezing potential of oxalic acid corroborate the findings from a recent study with emulsified aqueous solutions containing crystalline oxalic acid. In those experiments, the crystallisation of oxalic acid diyhdrate was triggered by a preceding homogeneous freezing
\end{abstract}

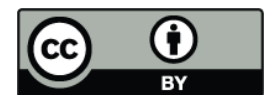

Correspondence to: R. Wagner (robert.wagner2@kit.edu) cycle with the emulsion samples. The expansion cooling cycles with ternary $\mathrm{H}_{2} \mathrm{SO}_{4} / \mathrm{OA} / \mathrm{H}_{2} \mathrm{O}$ solution droplets were aimed to analyse whether those findings can be transferred to ice nucleation experiments with airborne oxalic acid containing aerosol particles. Under our experimental conditions, the efficiency by which the surface of homogeneously nucleated ice crystals triggered the precipitation of oxalic acid dihydrate was very low, i.e., less than one out of a hundred ice crystals that were formed by homogeneous freezing in a first expansion cooling cycle left behind an ice-active organic crystal that acted as immersion freezing nucleus in a second expansion cooling cycle.

\section{Introduction}

Dicarboxylic acids are ubiquitous components of the watersoluble organic fraction of the tropospheric aerosol. Their contribution to the total particulate organic carbon typically ranges from $1-3 \mathrm{wt} \%$ in urban and semi-urban areas to up to $10 \mathrm{wt} \%$ in remote marine atmospheres (Kerminen et al., 2000, 1999). Oxalic acid (HOOC-COOH), malonic acid $\left(\mathrm{HOOC}-\mathrm{CH}_{2}-\mathrm{COOH}\right.$ ), and succinic acid (HOOC- $\left(\mathrm{CH}_{2}\right)_{2}-$ $\mathrm{COOH})$ are usually the most abundant species, partly comprising more than $80 \%$ of the total diacid mass concentrations (Kawamura et al., 1996). Apart from investigating their hygroscopic behaviour and ability to act as atmospheric cloud condensation nuclei, several recent studies have addressed the ice nucleation potential of solid low-molecular weight dicarboxylic acids. On the one hand, the dicarboxylic acids can nucleate ice directly from the vapour phase (deposition mode ice nucleation) provided that they are directly exposed to an ice supersaturated environment, e.g. in form of a crystalline coating layer that was formed by physical and chemical processing on prevalent particulates such as mineral dust and soot. At typical tropospheric relative humidities, diacids of low water solubility like oxalic and succinic

Published by Copernicus Publications on behalf of the European Geosciences Union. 
acid may, on the other hand, also be present as solids that are immersed in aqueous inorganic and/or organic solution droplets (Marcolli et al., 2004; Zobrist et al., 2006). These embedded crystals can act as ice nuclei in the immersion mode.

For both modes of ice nucleation, oxalic acid in form of its dihydrate has revealed the by far highest ice nucleation potential amongst a variety of other dicarboxylic acids investigated. Oxalic acid dihydrate particles deposited onto a hydrophobic cold stage at $233 \mathrm{~K}$ were found to be efficient deposition mode ice nuclei at critical ice saturation ratios in the range from 1.10 to 1.25 for total particulate surface areas from $2 \times 10^{-1}$ to $6 \times 10^{-4} \mathrm{~cm}^{2}$ (Kanji et al., 2008). In contrast, anhydrous malonic, succinic, glutaric, and adipic acid crystals did not act as deposition mode ice nuclei at temperatures above $243 \mathrm{~K}$ (Parsons et al., 2004). A poor ice nucleability at temperatures between 228 and $217 \mathrm{~K}$ was also detected for size-selected 50 and $100 \mathrm{~nm}$ diameter oxalic acid particles that were generated by atomisation of an aqueous solution and subsequent drying at $<5 \%$ RH (303 K) (Prenni et al., 2001). The oxalic acid particles probed by Prenni et al. (2001), however, were most probably not crystalline because they featured a continuous water uptake between 45 and $91 \%$ RH in independently conducted hygroscopic growth curve measurements. In view of refined H-TDMA (hygroscopicity tandem differential mobility analyser) investigations (Mikhailov et al., 2009), the spray-dried aerosol was presumably composed of either concentrated solution droplets or amorphous, gel-like particles. The observed high ice nucleability of oxalic acid dihydrate might be related to its hydrogen-bonded crystal lattice with the interconnected two molecules of hydration water, referred to as chemical bond requirement for heterogeneous ice nucleation by Pruppacher and Klett (1997). Recent studies, however, also emphasise the importance of the active-site requirement, meaning the availability of surface defects like cracks, steps, and dislocations or surface impurities that could promote the deposition of water vapour. In contrast to the results of Parsons et al. (2004), solid glutaric acid particles that were probed by Baustian et al. (2010) acted as deposition mode ice nuclei at temperatures between 235 and $218 \mathrm{~K}$ instead of undergoing deliquescence to form aqueous solution droplets. The ice nucleation ability of the generated glutaric acid particles increased with increasing temperature, with a threshold ice saturation ratio of 1.2 for ice nucleation at $235 \mathrm{~K}$. Parsons et al. (2004) had already speculated that the investigated dicarboxylic acids could be more important in ice cloud formation if the particles had more surface defects than those generated in their study.

In a recent cloud chamber study we have shown that also the ice nucleation ability of oxalic acid dihydrate particles is highly variable and depends on their formation mechanism (Wagner et al., 2010). Oxalic acid dihydrate crystals that were formed by nucleation from a gaseous oxalic acid/air mixture or by rapid crystallisation of highly supersaturated aqueous solution droplets at temperatures $\leq 244 \mathrm{~K}$ proved to be even more ice active in the deposition mode than the particles probed by Kanji et al. (2008), showing ice formation at threshold ice saturation ratios lower than 1.10. In contrast, oxalic acid dihydrate particles that had crystallised from less supersaturated solution droplets at a higher temperature and were then cooled to $244 \mathrm{~K}$ partly revealed no ice activity at all. We have suggested that the high variability in the ice nucleation potential is related to differences in the surface morphology and particle microstructure of the variously generated oxalic acid dihydrate crystals, a dependence that has been evidenced in previous ice nucleation experiments with e.g. crystalline ammonium sulphate particles (Zuberi et al., 2001).

Concerning the immersion mode ice nucleation potential of dicarboxylic acids, Zobrist et al. (2006) detected that homogeneous ice nucleation leads to the nucleation of crystalline organics in aqueous solution droplets. After having measured the homogeneous freezing temperature of emulsified aqueous solutions of oxalic, succinic, and adipic acid with a differential scanning calorimeter (DSC), the samples were heated above the eutectic melting point of the mixtures and then revealed a higher freezing temperature in a second cooling cycle. Only in the case of oxalic acid, however, the freezing temperature in the second cooling cycle was higher than the homogeneous freezing temperature of pure water, indicating that this compound, presumably precipitated as oxalic acid dihydrate, is able to act as a heterogeneous immersion mode ice nucleus. Oxalic acid dihydrate also proved to be ice-active in the immersion mode when precipitated from ternary aqueous solutions with sodium chloride, malonic acid, and sulphuric acid as additional solute species. In their summary section, Zobrist et al. (2006) state that the crystallisation of oxalic acid dihydrate occurs concurrently with or induced by ice freezing. As a plausible mechanism, oxalic acid dihydrate crystallises heterogeneously on the homogeneously nucleated ice crystals during the first cooling cycle. The trajectory for ice freezing experiments with emulsions in the temperature-composition plane deviates from that of cooling air parcels in the atmosphere because in the latter case the aerosol particles are directly susceptive to the ambient relative humidity and will correspondingly change their composition. In this manuscript, we present new ice nucleation experiments on the immersion freezing potential of oxalic acid which closely mimic the trajectory of a cooling air parcel in the atmosphere. For this purpose, we have conducted a series of expansion cooling cycles in the AIDA aerosol and cloud chamber of the Karlsruhe Institute of Technology. In order to compare our findings to those from Zobrist et al. (2006), we outline in the following section important differences in the experimental approaches between the expansion cooling and the emulsion freezing experiments. Section 2.1 describes the trajectories of AIDA ice nucleation experiments in the temperature - composition plane. In Sect. 2.2, differences to the emulsion freezing experiments 
from Zobrist et al. (2006) are evaluated to devise strategies for the AIDA ice nucleation experiments with airborne oxalic acid containing aerosol particles. Note that details of the technical operation of the AIDA chamber are summarised in chapter 3.

\section{Experimental strategies}

\subsection{Experimental trajectories of AIDA expansion cooling experiments}

In Fig. 1, the experimental trajectories of two feasible AIDA expansion cooling experiments are shown as green and blue lines. In our preceding ice nucleation experiments with binary oxalic acid/water solution droplets, we have always observed the crystallisation of aqueous oxalic acid solution droplets to oxalic acid dihydrate after adding the aerosol to the AIDA chamber at $T \leq 244 \mathrm{~K}$ and were therefore not able to simulate the envisaged experimental approach which requires that supercooled solution droplets are initially present. In this manuscript, however, we describe a set of experiments with ternary sulphuric acid/oxalic acid/water solution droplets that remained in a supercooled liquid state in the AIDA chamber. Thereby, repetitive expansion cooling cycles similar to the Zobrist et al. (2006) freezing experiments were feasible. Figure 1 shows the phase diagram for a ternary solution with an oxalic acid to sulphuric acid mass ratio of 1.14:5. The abscissa denotes the total solute concentration (wt $\%$ sulphuric acid $+w t \%$ oxalic acid). The initial composition of the injected aerosol particles in experiments A and B adjusts to the prevailing relative humidity. In the preparation of the expansion cooling cycles, the inner walls of the AIDA chamber are coated by a thin ice layer (see detailed description in Sect. 3) and, therefore, the initial aerosol compositions are given by points $\mathrm{A} 1$ and $\mathrm{B} 1$ on the ice melting-point curve in the aqueous solutions, yielding a total solute concentration of about 31 and $35 \mathrm{wt} \%$, respectively. To mimic the expansion cooling of rising air parcels in the atmosphere, the AIDA pressure is reduced by controlled pumping, leading to a decrease in the gas temperature of up to $10 \mathrm{~K}$, depending on the pumping speed. As a result of the increasing relative humidity during expansion cooling, the initially concentrated solution droplets will strongly dilute. The initial temperature of experiment A $(244 \mathrm{~K})$ is chosen in a way that saturation with respect to supercooled water is reached during the expansion before the gas temperature has dropped below the homogeneous freezing temperature of pure water droplets of about $237 \mathrm{~K}$. When exceeding $100 \% \mathrm{RH}$ after about 3 to $4^{\circ}$ of cooling (240-241 K, A2), the ternary solution droplets are activated to a cloud of almost pure supercooled water droplets. After the gas temperature drops below $237 \mathrm{~K}$ (A3) during the continued expansion, the droplet cloud starts to glaciate. In experiment $\mathrm{B}$ the procedure is started at $235 \mathrm{~K}$, below the homogeneous freezing temperature of pure water droplets.

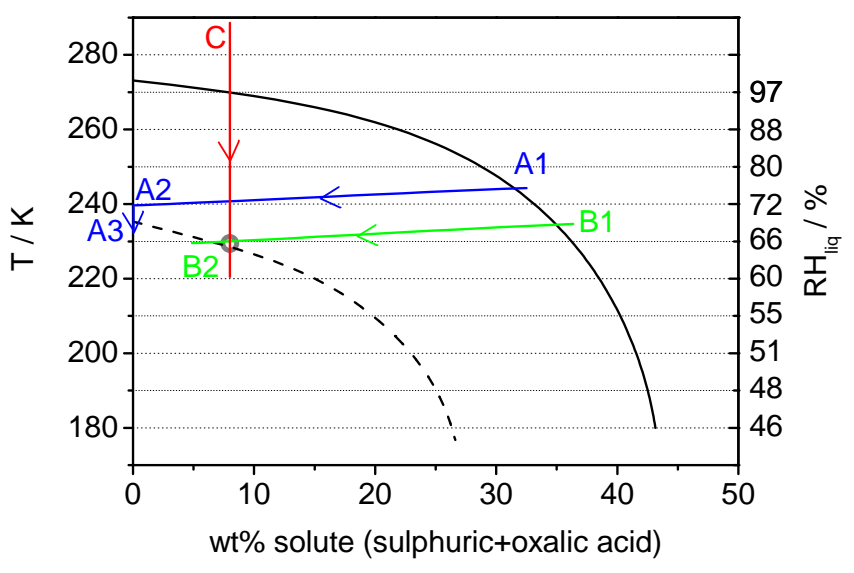

Fig. 1. Schematic experimental trajectories of various ice nucleation experiments with supercooled aqueous sulphuric/oxalic acid solution droplets in the temperature - composition plane, adapted from Wagner et al. (2010). The abscissa denotes the total solute concentration (wt $\%$ sulphuric acid $+\mathrm{wt} \%$ oxalic acid). The ice melting-point curve, shown as the black line, was calculated for an oxalic acid to sulphuric acid mass ratio of 1.14:5 with the Extended AIM Aerosol Thermodynamics Model II (Clegg et al., 1998; Clegg and Seinfeld, 2006a, b). The right y-axis denotes the prevailing relative humidity with respect to supercooled water, $\mathrm{RH}_{\text {liq }}$, for an environment that is saturated with respect to ice, i.e., when moving on the ice-melting point curve in the phase diagram. The red trajectory corresponds to the freezing experiment with emulsified solution droplets of $4 \mathrm{wt} \%$ sulphuric acid and $4 \mathrm{wt} \%$ oxalic acid by Zobrist et al. (2006) which homogeneously froze at $229.4 \mathrm{~K}$ in the first cooling cycle, as indicated by the grey circle. In lack of further freezing temperature measurements for different compositions in the ternary system, the dashed black line denotes the critical ice nucleation temperatures as a function of solute concentration for pure sulphuric acid solution droplets from the study by Koop et al. (1998). The blue and green trajectories represent expansion cooling experiments with airborne particles in the AIDA cloud chamber, see text for details.

So the ternary solution droplets will not dilute to almost pure water droplets but will homogeneously freeze once the solute concentration has fallen below a critical threshold value (B2).

After the ice cloud formation in experiments A and B, the pumping is stopped and the ice crystals slowly evaporate on a timescale of typically 10 to $15 \mathrm{~min}$. During this time period, the available ice particle surface may trigger the precipitation of oxalic acid dihydrate from the unfrozen ternary sulphuric acid/oxalic acid/water solutions. These solutions might be included within the nucleated ice crystals or form a liquid film on their surface. After the ice crystals have completely evaporated, second expansion cooling cycles with the same aerosol load are again started at 244 and $235 \mathrm{~K}$ to probe whether the homogeneous freezing event has indeed triggered the crystallisation of oxalic acid dihydrate. The nucleated organic particulates could act as immersion freezing nuclei in experiment $\mathrm{B}$, thereby inducing earlier ice formation compared to the preceding homogeneous freezing 
run. Also in experiment $A$, the aerosol particles could be ice-active in the immersion mode and induce freezing before water saturation is reached at point A2 of the trajectory. In case of lower heterogeneous ice nucleability, the aerosol particles will again be activated to a droplet cloud at point A2. Our previous experiments have shown that potentially immersed oxalic acid dihydrate crystals might then not get instantly and completely dissolved on the typical timescale of an expansion cooling experiment (Wagner et al., 2010). The embedded crystals therefore still can act as condensation mode ice nuclei in this experiment and could provoke the glaciation of the droplet cloud before the homogeneous freezing temperature of pure water droplets has been reached at point $\mathrm{A} 3$.

\subsection{Comparison with emulsion freezing experiments and envisaged strategies for the AIDA experiments}

In this section, we want to stress an important difference between the AIDA and the Zobrist et al. (2006) experiments, namely the ability to detect the potentially precipitated oxalic acid dihydrate particles in the second cooling cycles. For the experiments with emulsified aqueous solutions by Zobrist et al. (2006), it is reasonable to assume that all droplets of the emulsion will homogeneously freeze in the first cooling cycle. The emulsions are then slowly heated with $1 \mathrm{~K} \mathrm{~min}^{-1}$ to the conditioning temperature of $279 \mathrm{~K}$. For an overall time period of about one hour, the ice crystals and the remaining unfrozen supersaturated solutions containing oxalic acid are in contact. The exemplarily shown exothermic ice freezing peak in the DSC heat flow record (see Fig. 1 in their publication) that was monitored during the second freezing cycle almost shows the same shape (peak height and peak area) compared to the first freezing cycle, i.e., the exothermic peak is shifted as a whole towards a clearly higher freezing temperature. This suggests that the outlined experimental conditions must have led to the precipitation of an ice-active oxalic acid dihydrate crystal in the vast majority of the droplets of the emulsion.

In contrast, heterogeneous ice nucleation induced by potentially precipitated oxalic acid dihydrate particles in the second expansion cooling cycles in the AIDA chamber experiments will only be detectable for a low number fraction of the initially added supercooled solution droplets. In the course of trajectory A, all seed aerosol particles will be activated to cloud droplets when reaching water saturation at point A2. Upon glaciation of the droplet cloud at about $237 \mathrm{~K}$, however, ice crystals that have started to nucleate first in the chamber volume will grow at the expense of still unfrozen cloud droplets via the Bergeron-Findeisen process. The diameters of the cloud droplets roughly cover one order of magnitude on the size scale (typically $1-10 \mu \mathrm{m}$ ), corresponding to a variation in the homogeneous ice nucleation rate, if volume-dominated, by three orders of magnitude. During an expansion cooling cycle, the relative humid- ity starts to drop below $100 \%$ and causes the remaining cloud droplets to evaporate before they all have a chance to freeze (Benz et al., 2005). Even for the highest employable pumping speed or cooling rate, the absolute number concentration of nucleated ice crystals is thereby limited to a value of about $100 \mathrm{~cm}^{-3}$, irrespective of the seed aerosol number concentration that is typically between $10^{3}$ and $10^{4} \mathrm{~cm}^{-3}$. Concerning experiment $\mathrm{B}$, only supercooled solution droplets in a narrow range of the overall size distribution at around $1 \mu \mathrm{m}$ will homogeneously freeze at point B2; see Fig. 8 in Haag et al. (2003) and Fig. 3 in Wagner et al. (2008). Larger droplets remain liquid because their water activity lags behind the equilibrium value due to kinetic growth limitations. Smaller droplets retain a higher solute concentration due to the Kelvin effect. The frozen droplets will rapidly deplete the excess of water vapour in the gas phase and prevent further solution droplets from freezing. Likewise to experiment A, the maximum ice particle number concentration, independent of the reservoir of seed aerosol particles, is thereby also limited to about $100 \mathrm{~cm}^{-3}$. Let us assume that in $10 \%$ of these nucleated ice crystals the precipitation of oxalic acid dihydrate might be triggered during their residence time of about $10-15 \mathrm{~min}$ in the chamber. Then, only up to 10 particles per $\mathrm{cm}^{3}$ AIDA volume would contain a solid nucleus before starting the second expansion cooling cycles. Not necessarily all of these embedded crystals will act as a heterogeneous immersion mode ice nucleus. Again assuming an ice-active fraction of $10 \%$, one would obtain an ice particle number concentration of $1 \mathrm{~cm}^{-3}$ that is formed by heterogeneous nucleation in the second freezing cycles. Although this is above the threshold number concentration of about $0.1 \mathrm{~cm}^{-3}$ for our ice diagnostic instruments, the differences between the first and second cooling cycles in the AIDA are expected to be much less pronounced in comparison with the repetitive emulsion freezing cycles. In case that the yield of ice-active oxalic acid nuclei from the first nucleation event would be even lower than estimated above, no change in the ice nucleation behaviour could be monitored.

Before addressing the experiments with ternary sulphuric acid/oxalic acid/water solution droplets in Sect. 4.2, we therefore describe in Sect. 4.1 a set of benchmark experiments with an aerosol population where indeed each individual particle contained a solid oxalic acid (dihydrate) nucleus. These experiments address another pathway that could lead to the precipitation of low-soluble organics within aqueous solution droplets in the atmosphere. An air parcel containing aqueous solution droplets of inorganic solutes like sodium chloride and/or ammonium sulphate in a mixture with small amounts of oxalic acid might at least temporarily be exposed to such a low relative humidity $(\mathrm{RH})$ that efflorescence of the inorganic component can occur. The matrix of the crystallized inorganic particulates could then also trigger the precipitation of oxalic acid dihydrate whereas binary oxalic acid/water solution droplets have frequently been observed to be difficult to effloresce even at relative humidities $<5 \%$ 
(Braban et al., 2003; Mikhailov et al., 2009; Prenni et al., 2001). When entering a regime with a higher relative humidity, the inorganic components might again get dissolved at the deliquescence point which, for a multi-component mixture, can be well below the deliquescence relative humidities of the pure compounds (Marcolli et al., 2004; Wexler and Seinfeld, 1991). In contrast to dicarboxylic acids with a high solubility in water like e.g. malonic acid and maleic acid, less soluble compounds like oxalic acid and succinic acid do not notably affect the deliquescence behaviour of the other solutes and remain as solid inclusions within the droplets even at elevated humidity levels (Brooks et al., 2002; Choi and Chan, 2002; Lightstone et al., 2000; Marcolli et al., 2004; Treuel et al., 2008). In the AIDA, we have investigated the ternary system sodium chloride, oxalic acid, and water. Reference expansion experiments that were conducted with bare effloresced sodium chloride particles at 244 and $235 \mathrm{~K}$ revealed that the inorganic crystals did not act as deposition mode ice nuclei but underwent a deliquescence transition to form aqueous solution droplets at about $72 \pm 3 \% \mathrm{RH}$ which then, later on during the expansion, homogeneously froze as almost pure water droplets or dilute aqueous solution droplets at respective points A3 and B2 in the sodium chloride-water phase diagram (see Fig. 1). Performing these expansion experiments with mixed effloresced particles of sodium chloride and small amounts of oxalic acid, we will obtain an aerosol population of oxalic acid crystallites immersed in aqueous solution droplets after exceeding the deliquescence relative humidity of the inorganic salt. Thereby, we can investigate the ice nucleability of oxalic acid in the immersion mode with an ensemble of aerosol particles that all contain a solid nucleus. Based on these results, we will then analyse the efficiency by which oxalic acid crystals can precipitate from supercooled aqueous solution droplets via homogeneous ice nucleation.

\section{Methods}

\subsection{The AIDA facility as a moderate expansion cloud chamber for ice nucleation studies}

The centre of the AIDA facility at the Karlsruhe Institute of Technology is its $84 \mathrm{~m}^{3}$ sized aluminium chamber that is located inside a large, thermally insulated housing whose interior can be cooled to any temperature between ambient and $183 \mathrm{~K}$ (Fig. 2). A mixing fan, located at the bottom of the chamber, is continuously operating throughout the experiments for providing homogeneous conditions in terms of temperature, relative humidity, as well as aerosol and cloud particle number concentration inside the aerosol vessel. Under stirred conditions, the spatial temperature variability inside the vessel, as monitored by lines of horizontally and vertically arranged temperature sensors, is less than $\pm 0.3 \mathrm{~K}$. In the preparation of an expansion run to be started at a given

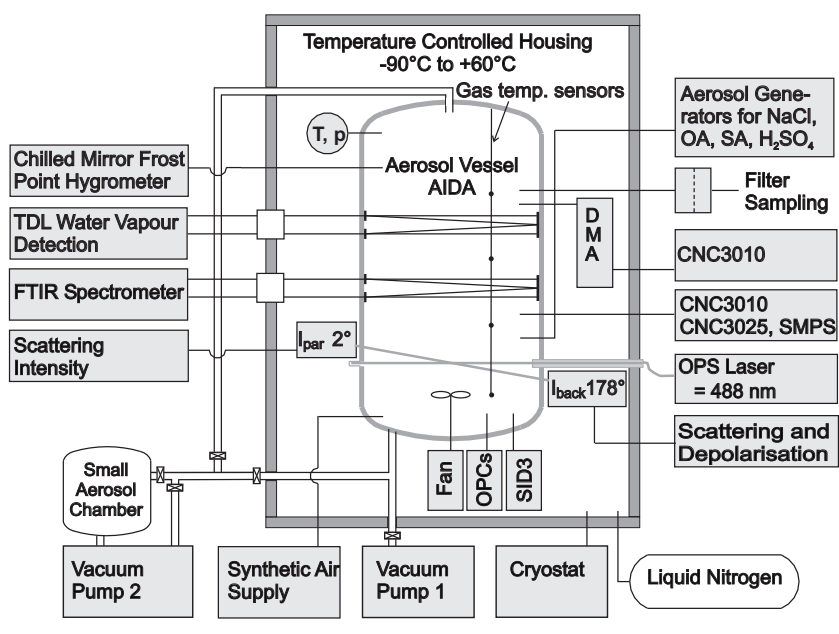

Fig. 2. Schematic cross section of the AIDA facility with the main instrumentation for the ice nucleation experiments in the ternary $\mathrm{NaCl} / \mathrm{OA} / \mathrm{H}_{2} \mathrm{O}$ and $\mathrm{H}_{2} \mathrm{SO}_{4} / \mathrm{OA} / \mathrm{H}_{2} \mathrm{O}$ systems.

temperature $T_{\text {start }}$, the chamber, initially kept at a temperature higher than $T_{\text {start }}$, is evacuated with two vacuum pumps to a final pressure of about $0.01 \mathrm{hPa}$, followed by a series of flushing cycles with particle-free synthetic air to ensure aerosol free experimental conditions. The background particle number concentration is usually less than $0.1 \mathrm{~cm}^{-3}$. Then, a certain amount of purified water is evaporated into the evacuated chamber. The water used for AIDA experiments is first treated by reverse osmosis (RO10, Werner) and then further purified using a filter cascade (NANOpure Infinity, Barnstead). Upon cooling to $T_{\text {start }}$ and refilling the chamber with synthetic air to ambient pressure, the excess water vapour forms an ice layer at the inner chamber walls. Thereby, the relative humidity is close to an ice saturation ratio $S_{\text {ice }}$ of one before the expansion run is started. $S_{\text {ice }}$ is defined as the quotient of the prevailing water vapour pressure $p_{\mathrm{w}}(T)$ and the saturation pressure over ice $p_{\mathrm{w}, \text { ice }}(T)$, $S_{\text {ice }}=p_{\mathrm{w}}(T) / p_{\mathrm{w} \text {,ice }}(T)$. At a closer look, $S_{\text {ice }}$ is typically in the range from 0.90 to 0.95 at static pressure and temperature conditions prior to the expansion cooling cycle because the gas temperature is always a few tenths of a Kelvin higher than the temperature of the ice-covered walls due to some internal heat sources (heating foils, heated sampling tubes, mixing fan). Finally, the desired seed aerosol particles whose ice nucleability will be investigated are added to the chamber (see Sect. 3.2).

To mimic the expansion cooling of rising air parcels in the atmosphere and to establish supersaturations with respect to the ice phase, the AIDA pressure is reduced by controlled pumping. Depending on the pumping speed, cooling rates between 4 and $0.1 \mathrm{~K} \mathrm{~min}^{-1}$ can be controlled. Note that the wall temperature almost stays constant during AIDA expansion experiments. Thereby, Poisson's equation for adiabatic cooling is only obeyed at the very beginning 
of an expansion cooling run and the maximum decrease in the AIDA gas temperature is limited to about $10 \mathrm{~K}$ because the increasing temperature gradient between the well-mixed chamber interior and the walls increases the heat flux to the chamber volume (Wagner et al., 2006b). Upon cooling, $p_{\mathrm{w}, \text { ice }}(T)$ decreases exponentially with the gas temperature whereas $p_{\mathrm{w}}(T)$ decreases at most linearly with the total pressure. The humidification rate, $d S_{\text {ice }} / d t$, of typically $0.2 \mathrm{~min}^{-1}$ for a medium pumping speed of $120 \mathrm{~m}^{3} \mathrm{~h}^{-1}$ is further enhanced by evaporation of ice from the warm chamber walls. Ice nucleation eventually occurs when the relative humidity has exceeded the aerosol-specific critical threshold ice saturation ratio $S_{\text {ice, crit }}$.

A comprehensive set of instruments for humidity measurements and ice crystal diagnostics is located on four separate floors surrounding the thermostated housing (Fig. 2). A detailed instrument description is given in the recent review by Wagner et al. (2009) and in our companion paper on the ice nucleability of oxalic acid dihydrate (Wagner et al., 2010). In the following, we therefore only give a brief summary of the key components of the AIDA instrumentation. $p_{\mathrm{w}}(T)$ is measured in situ with tuneable diode laser (TDL) absorption spectroscopy by scanning a selected rovibrational water vapour transition at around $1370 \mathrm{~nm}$. The time evolution of the saturation ratios with respect to ice $\left(S_{\text {ice }}\right)$ and supercooled water $\left(S_{\text {liq }}\right)$ is then obtained by dividing $p_{\mathrm{w}}(T)$ through the saturation water vapour pressures over ice and liquid water, as calculated with the equations from Murphy and Koop (2005) for the measured spatial means of the AIDA gas temperature. The absolute accuracy of the TDL measurements is dominated by the line strength uncertainty of $\pm 3 \%$ (Wagner et al., 2008). In addition to the interstitial gas-phase water concentration, the total water concentration is measured as well, comprising the sum of interstitial water and particle water that is evaporated before the measurement is done. The total water concentration is measured ex situ with a fast high precision chilled mirror hygrometer (MBW, model 373) that samples through a heated sampling tube. Cloud particles (either supercooled droplets and/or ice crystals) are counted and sized by two optical particle counters (OPC1 and OPC2, type WELAS2000, Palas) in the size range from $0.7-40 \mu \mathrm{m}$ (OPC1) and 2.3-104 $\mu \mathrm{m}$ (OPC2). In situ laser light scattering and depolarisation measurements as well as FTIR extinction measurements are further powerful tools to detect the nucleation and growth of the cloud particles and to distinguish between spherical supercooled cloud droplets and aspherical ice crystals. The records from the light scattering measurements with a $488 \mathrm{~nm}$ semiconductor laser (Coherent) that is directed horizontally through the AIDA chamber are the scattered light intensities in the forward $\left(I_{\text {for }}\right.$, scattering angle $\left.2^{\circ}\right)$ and backward $\left(I_{\text {back }}\right.$, scattering angle $\left.178^{\circ}\right)$ direction. The backscattered light is detected and polarisation-resolved with $I_{\text {back,par }}$ and $I_{\text {back,per }}$ denoting the backscattered intensities parallel and perpendicular to the incident polarisation state of the light beam. The backscattering linear depolar- isation ratio $\delta$ is then obtained by $\delta=I_{\text {back,per }} / I_{\text {back,par. }} \delta$ is zero for light scattering by spherical cloud droplets and, apart from very small or highly aspherical particles, different from zero for light scattering by aspherical ice crystals, thereby featuring a strong dependency on the particle size and shape (Mishchenko et al., 1996; Zakharova and Mishchenko, 2000). Infrared extinction of the cloud particles is measured between 6000 and $800 \mathrm{~cm}^{-1}$ at $4 \mathrm{~cm}^{-1}$ resolution with a FTIR spectrometer that is coupled to an internal White-type multiple reflection cell. Fitting algorithms are used to retrieve the number size distributions of the cloud particles from their measured infrared extinction spectra as outlined in Wagner et al. (2006a), thereby exploiting the different spectral habitus of the absorption bands of liquid water droplets and ice crystals to detect the glaciation of a droplet cloud (Zasetsky et al., 2005). The light scattering and infrared measurements are also valuable tools for the characterisation of the seed aerosol particles with respect to e.g. their phase (solid or liquid) and chemical composition, as will be repeatedly shown in the current work.

\subsection{Aerosol generation and characterisation}

In the present study, we have investigated the ternary systems sodium chloride/oxalic acid/water $\left(\mathrm{NaCl} / \mathrm{OA} / \mathrm{H}_{2} \mathrm{O}\right)$ and sulphuric acid/oxalic acid/water $\left(\mathrm{H}_{2} \mathrm{SO}_{4} / \mathrm{OA} / \mathrm{H}_{2} \mathrm{O}\right)$ as seed aerosols in expansion cooling experiments. $\mathrm{NaCl} / \mathrm{OA} / \mathrm{H}_{2} \mathrm{O}$ aerosol particles of three different $\mathrm{OA}: \mathrm{NaCl}$ mass ratios were generated from aqueous solutions of $5 \mathrm{wt} \% \mathrm{NaCl}$ and 0.07 , 0.36 , and $0.51 \mathrm{wt} \% \mathrm{OA}$, prepared by dissolving sodium chloride (Merck, $>99.5 \%, 58.44 \mathrm{~g} \mathrm{~mol}^{-1}$ ) and oxalic acid dihydrate (Merck, $>99.5 \%, 126.07 \mathrm{~g} \mathrm{~mol}^{-1}$ ) in purified water. In two additional experiments, a binary salt solution of $5 \mathrm{wt} \% \mathrm{NaCl}$ and a quaternary solution of $5 \mathrm{wt} \%$ $\mathrm{NaCl}, 0.36 \mathrm{wt} \% \mathrm{OA}$, and $0.1 \mathrm{wt} \%$ succinic acid (SA, Merck, $>99.5 \%, 118.09 \mathrm{~g} \mathrm{~mol}^{-1}$ ) were employed. The solutions were filtrated by a submicron syringe filter (PTFE) to remove any undissolved particulates and were subsequently injected into the AIDA chamber at $T=244 \mathrm{~K}$ and $\mathrm{RH}=70 \%$ with an ultrasonic nebuliser (GA2400, Sinaptec). As already known from previous crystallisation experiments with supersaturated salt solution droplets, the ensemble of injected aqueous solution droplets does not remain in a supercooled liquid state in AIDA under such conditions but gradually crystallises on a time scale of several hours (see Sect. 4.1). The size distribution of such generated mixed effloresced particles of sodium chloride and oxalic acid was measured with a scanning mobility particle sizer (SMPS, TSI) and an aerodynamic particle spectrometer (APS, TSI). In all experiments the median particle diameter was about $0.7 \mu \mathrm{m}$; an exemplary size distribution measurement of effloresced $\mathrm{NaCl}$ particles is shown in Fig. 3 (left panel). Typical number concentrations, obtained after an overall injection period of about $30 \mathrm{~min}$ and measured with a condensation particle counter (CPC3010, TSI), were in the range from 400 to $600 \mathrm{~cm}^{-3}$. 

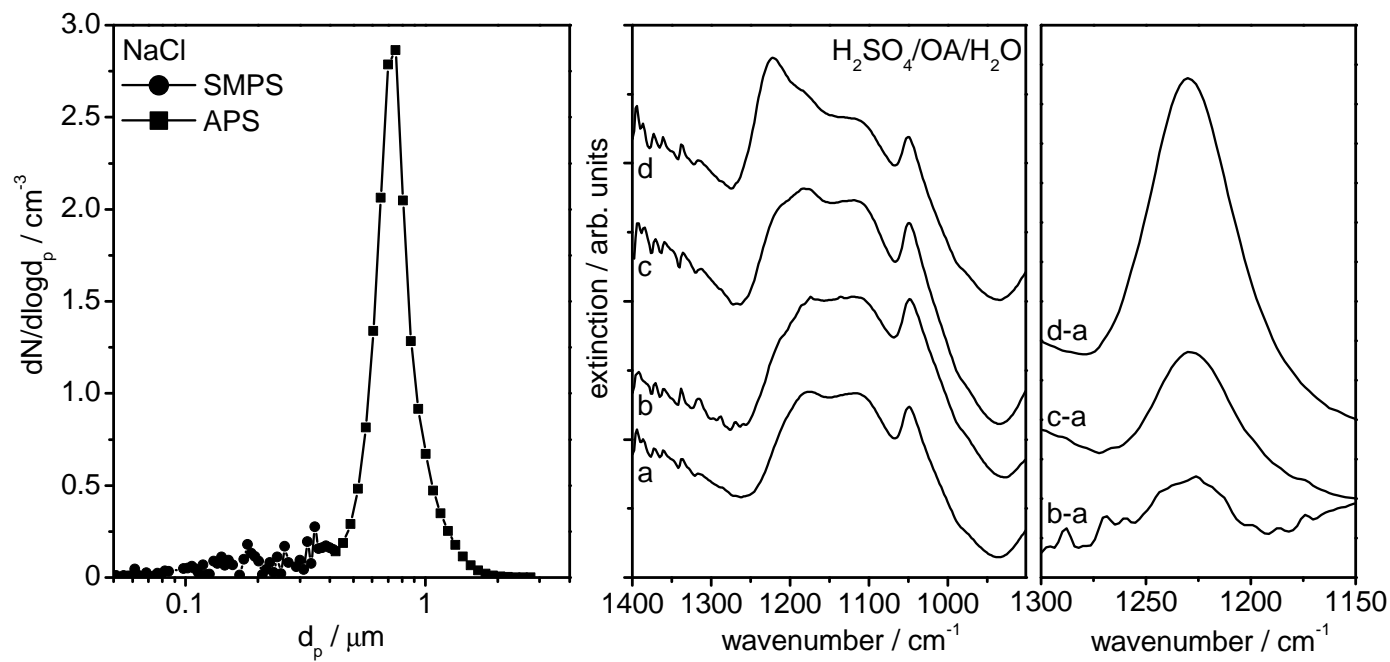

Fig. 3. Left panel: Normalised number size distribution of effloresced $\mathrm{NaCl}$ particles from Exp. 1 (Table 1) obtained by combination of SMPS and APS measurements. Middle Panel: Infrared extinction spectra of binary aqueous sulphuric acid solution droplets (Exp. 6, trace a) and three ternary $\mathrm{H}_{2} \mathrm{SO}_{4} / \mathrm{OA} / \mathrm{H}_{2} \mathrm{O}$ solution droplets with $\mathrm{OA}$ to $\mathrm{H}_{2} \mathrm{SO}_{4}$ mass ratios of 0.51:5 (trace b, Exp. 7), 1.14:5 (trace c, Exp. 8), and 3.43:5 (trace d, Exp. 9), recorded after spraying the respective aqueous solutions into the AIDA chamber at about $265 \mathrm{~K}$ and $90 \%$ RH. The spectra are offset for clarity. Right panel: Difference spectra of the traces b, c, and d shown in the middle panel in relation to spectrum a in the regime of the $\mathrm{C}-\mathrm{O}$ stretching mode of aqueous oxalic acid (enlarged y-axis compared to the middle panel).

In the $\mathrm{H}_{2} \mathrm{SO}_{4} / \mathrm{OA} / \mathrm{H}_{2} \mathrm{O}$ system, three different aqueous solutions with $5 \mathrm{wt} \% \mathrm{H}_{2} \mathrm{SO}_{4}$ as well as $0.51,1.14$, and $3.43 \mathrm{wt} \%$ OA were prepared, supplemented by a binary reference solution of $5 \mathrm{wt} \% \mathrm{H}_{2} \mathrm{SO}_{4}$. The aqueous solutions were directly sprayed into the cloud chamber via a two-component jet device (model 970 from Düsen-Schlick GmbH, Germany). It uses a particle free synthetic air flow of about $11 \mathrm{~min}^{-1}$ at an absolute pressure of 2 bar to disperse a liquid flow of about 5 to $10 \mathrm{ml} \mathrm{min}^{-1}$ (Möhler et al., 2008). An injection period of $5 \mathrm{~s}$ typically yielded aerosol number concentrations in the order of $10^{4}$ particles $\mathrm{cm}^{-3}$ after homogeneous conditions were achieved throughout the chamber volume. The AIDA vessel was kept at about $265 \mathrm{~K}$ during injection and thereafter cooled to $244 \mathrm{~K}$, i.e., to the starting temperature of the first expansion run (trajectory A in Fig. 1). This was done to avoid ice formation during aerosol addition that might occur as a result of the nozzle expansion if the temperature is too close to the homogeneous freezing temperature of the droplets. The number size distribution of the injected droplets was retrieved from their simultaneously recorded infrared extinction spectra. Best fit results were obtained for broad, log-normal type number size distributions with mode widths $\sigma_{g}$ of about 2.0 and median droplet diameters of about $0.5 \mu \mathrm{m}$. The middle panel of Fig. 3 shows subsets of the infrared extinction spectra of the binary $\mathrm{H}_{2} \mathrm{SO}_{4} / \mathrm{H}_{2} \mathrm{O}$ and the three ternary $\mathrm{H}_{2} \mathrm{SO}_{4} / \mathrm{OA} / \mathrm{H}_{2} \mathrm{O}$ solution droplets which were recorded immediately after aerosol addition. In addition to the extinction bands due to the $\mathrm{HSO}_{4}^{-}$and $\mathrm{SO}_{4}^{2-}$ ions that are visible in the bottom spectrum, the spectra of the ternary solution droplets also contain the $\mathrm{C}-\mathrm{O}$ stretching mode of aqueous oxalic acid at around $1240 \mathrm{~cm}^{-1}$ (Braban et al., 2003), as can be seen more closely in the difference spectra that are shown in the right panel. During cooling, the $\mathrm{H}_{2} \mathrm{SO}_{4} / \mathrm{OA} / \mathrm{H}_{2} \mathrm{O}$ droplets will concentrate according to the course of the ice-melting point curve in the phase diagram (see Fig. 1). At the starting point of trajectory A ( $244 \mathrm{~K}$, typically $70 \% \mathrm{RH}$ with respect to supercooled water), the solute weight fractions in the three different ternary experiments, according to calculations with the Extended AIM Aerosol Thermodynamics Model II (Clegg et al., 1998; Clegg and Seinfeld, 2006a, b), are $29.6 \mathrm{wt} \% \mathrm{H}_{2} \mathrm{SO}_{4} / 3.0 \mathrm{wt} \%$ OA, $28.2 \mathrm{wt} \% \mathrm{H}_{2} \mathrm{SO}_{4} / 6.4 \mathrm{wt} \%$ $\mathrm{OA}$, and $24.0 \mathrm{wt} \% \mathrm{H}_{2} \mathrm{SO}_{4} / 16.5 \mathrm{wt} \% \mathrm{OA}$. At the starting point of trajectory B with $T=235 \mathrm{~K}$ and $\mathrm{RH}=63 \%$, solute concentrations of $32.3 \mathrm{wt} \% \mathrm{H}_{2} \mathrm{SO}_{4} / 3.3 \mathrm{wt} \% \mathrm{OA}, 30.7 \mathrm{wt} \%$ $\mathrm{H}_{2} \mathrm{SO}_{4} / 7.0 \mathrm{wt} \% \mathrm{OA}$, and $26.1 \mathrm{wt} \% \mathrm{H}_{2} \mathrm{SO}_{4} / 18.0 \mathrm{wt} \%$ OA are obtained. As shown by experiments on the solubility and decomposition of oxalic acid in aqueous solutions of sulphuric acid at room temperature (Herz and Neukirch, 1923), degradation was not detected up to a 3.5 molar $\mathrm{H}_{2} \mathrm{SO}_{4}$ solution ( $28 \mathrm{wt} \% \mathrm{H}_{2} \mathrm{SO}_{4}$ ) for observation times of $30-40 \mathrm{~h}$. Also for higher sulphuric acid concentrations, only a minor degradation of oxalic acid could be monitored. We therefore assume that decomposition of oxalic acid will not occur in our low-temperature experiments because the maximum sulphuric acid concentrations are, at most, only slightly above the threshold value where the onset of degradation has been observed at room temperature. 
Table 1. Compilation of the various ice nucleation experiments in the five investigated systems $\mathrm{NaCl} / \mathrm{H}_{2} \mathrm{O}, \mathrm{NaCl} / \mathrm{OA} / \mathrm{H}_{2} \mathrm{O}$, $\mathrm{NaCl} / \mathrm{OA} / \mathrm{SA} / \mathrm{H}_{2} \mathrm{O}, \mathrm{H}_{2} \mathrm{SO}_{4} / \mathrm{H}_{2} \mathrm{O}$, and $\mathrm{H}_{2} \mathrm{SO}_{4} / \mathrm{OA} / \mathrm{H}_{2} \mathrm{O}$. The procedure for each experiment is discussed in detail in Sect. 4.

\begin{tabular}{|c|c|c|c|}
\hline Exp. & Solute(s) & $\begin{array}{l}\text { Mass ratio } \\
\text { of solutes }\end{array}$ & $\begin{array}{l}\text { Experimental procedure/ } \\
\text { Number of expansion cooling cycles }\end{array}$ \\
\hline 1 & $\mathrm{NaCl}$ & - & $\begin{array}{l}\text { Aerosol addition at } 244 \mathrm{~K} \text {. Observation of crystallisation } \\
\text { for about } 5 \mathrm{~h} \text {, followed by expansion } \\
\text { cooling cycle at } 244 \mathrm{~K} \text {. Cooling of the chamber } \\
\text { to } 235 \mathrm{~K} \text { and expansion cooling cycle at } 235 \mathrm{~K} \text {. }\end{array}$ \\
\hline $2 \mathrm{a}$ & $\mathrm{OA}, \mathrm{NaCl}$ & $0.51: 5$ & Same procedure as in Exp. 1. \\
\hline $2 b$ & $\mathrm{OA}, \mathrm{NaCl}$ & $0.51: 5$ & $\begin{array}{l}\text { Aerosol addition at } 244 \mathrm{~K} \text {. Observation of crystallisation } \\
\text { for about } 5 \mathrm{~h} \text {, followed by expansion cooling cycle at } 244 \mathrm{~K} \text {. } \\
\text { Again observation of crystallisation and } \\
\text { another expansion cooling cycle at } 244 \mathrm{~K} \text {. }\end{array}$ \\
\hline 3 & $\mathrm{OA}, \mathrm{NaCl}$ & $0.36: 5$ & Same procedure as in Exp. 1. \\
\hline 4 & $\mathrm{OA}, \mathrm{NaCl}$ & $0.07: 5$ & Same procedure as in Exp. 1. \\
\hline 5 & $\mathrm{SA}, \mathrm{OA}, \mathrm{NaCl}$ & $0.1: 0.36: 5$ & $\begin{array}{l}\text { Aerosol addition at } 244 \mathrm{~K} \text {. Observation of crystallisation } \\
\text { for about } 5 \mathrm{~h} \text {, followed by expansion cooling cycle at } 244 \mathrm{~K} \text {. } \\
\text { No further cooling as in Exp. } 1 .\end{array}$ \\
\hline 6 & $\mathrm{H}_{2} \mathrm{SO}_{4}$ & - & $\begin{array}{l}\text { Aerosol addition at } 265 \mathrm{~K} \text {, cooling of the chamber to } \\
244 \mathrm{~K} \text { and two repetitive expansion cooling cycles at } 244 \mathrm{~K} \text {. } \\
\text { Cooling of the chamber to } 235 \mathrm{~K} \text { and expansion cooling cycle at } 235 \mathrm{~K} \text {. }\end{array}$ \\
\hline 7 & $\mathrm{OA}, \mathrm{H}_{2} \mathrm{SO}_{4}$ & $0.51: 5$ & $\begin{array}{l}\text { Aerosol addition at } 265 \mathrm{~K} \text {, cooling of the chamber to } 244 \mathrm{~K} \text { and } \\
\text { two repetitive expansion cooling cycles at } 244 \mathrm{~K} \text {. Cooling of the } \\
\text { chamber to } 235 \mathrm{~K} \text { and two repetitive expansion cooling cycles at } 235 \mathrm{~K} \text {. } \\
\text { Warming of the chamber to } 244 \mathrm{~K} \text { and another } \\
\text { expansion cooling cycle at } 244 \mathrm{~K} \text {. }\end{array}$ \\
\hline 8 & $\mathrm{OA}, \mathrm{H}_{2} \mathrm{SO}_{4}$ & $1.14: 5$ & $\begin{array}{l}\text { Aerosol addition at } 265 \mathrm{~K} \text {, cooling of the chamber to } 244 \mathrm{~K} \text { and } \\
\text { two repetitive expansion cooling cycles at } 244 \mathrm{~K} \text {. Cooling of the } \\
\text { chamber to } 235 \mathrm{~K} \text { and three repetitive expansion cooling cycles at } 235 \mathrm{~K} \text {. } \\
\text { Warming of the chamber to } 244 \mathrm{~K} \text { and another expansion cooling cycle at } 244 \mathrm{~K} \text {. }\end{array}$ \\
\hline 9 & $\mathrm{OA}, \mathrm{H}_{2} \mathrm{SO}_{4}$ & $3.43: 5$ & $\begin{array}{l}\text { Aerosol addition at } 265 \mathrm{~K} \text {, cooling of the chamber to } 244 \mathrm{~K} \text { and } \\
\text { two repetitive expansion cooling cycles at } 244 \mathrm{~K} \text {. }\end{array}$ \\
\hline
\end{tabular}

Concluding this section, Table 1 presents a summary of the ice nucleation experiments that were performed in the present study, serving as a look-up table for the detailed discussion in chapter 4 . The first column denotes the experiment number, the second and third columns list the employed solute species ( $\left.\mathrm{NaCl}, \mathrm{OA}, \mathrm{SA}, \mathrm{H}_{2} \mathrm{SO}_{4}\right)$ as well as their relative mass ratio, and the final column briefly describes the experimental procedure with the number of expansion cooling runs that were performed at various AIDA temperatures.

\section{Results and discussion}

\subsection{Ice nucleation studies in the ternary $\mathrm{NaCl} / \mathrm{OA} / \mathrm{H}_{2} \mathrm{O}$ system}

This section comprises the analysis of the ice nucleation experiments 1-5 from Table 1 and is divided into four subsections. In Sect. 4.1.1, we describe the hygroscopic behaviour and ice nucleation potential of effloresced $\mathrm{NaCl}$ particles (Exp. 1) in expansion cooling cycles that were started at 244 and $235 \mathrm{~K}$. Section 4.1 .2 contains a thorough analysis of the results for the ternary system from Exps. $2 \mathrm{a}$ and 2b. The findings from the subsequent ternary experiments 3, 4, and 5 are then assessed more concisely in Sect. 4.1.3. The concluding Sect. 4.1.4 summarises all results, compares 
them to those from Zobrist et al. (2006), and evaluates their significance with respect to the envisaged experiments in the ternary $\mathrm{H}_{2} \mathrm{SO}_{4} / \mathrm{OA} / \mathrm{H}_{2} \mathrm{O}$ system which are then presented in Sect. 4.2.

\subsubsection{Reference: ice nucleation study in the binary $\mathrm{NaCl} / \mathrm{H}_{2} \mathrm{O}$ system (Exp. 1)}

As indicated in the introduction, the solid $\mathrm{NaCl}$ particles were formed by crystallisation of aqueous $\mathrm{NaCl}$ solution droplets that were added to the AIDA chamber at $244 \mathrm{~K}$ and $70 \%$ RH with respect to supercooled water. The bottom left panel in Fig. 4 shows the trace of the depolarisation ratio $\delta$ that was monitored upon spraying the aqueous solution of $5 \mathrm{wt} \% \mathrm{NaCl}$ into the AIDA vessel with the ultrasonic nebuliser. With the start of aerosol addition, $\delta$ immediately adopts a small background value of about 0.02 that is typically observed when spherical droplets are present in the chamber. The slight deviation from zero is due to Rayleigh scattering by air molecules, a less than $100 \%$ linear polarisation of the laser light, and minor misalignments of the polarisers in the optical set-up. Already during the injection period, as well as in the course of the following observation period of about $4 \mathrm{~h}, \delta$ continuously increases due to the formation of aspherical $\mathrm{NaCl}$ crystals. Efflorescence is also documented by the loss of the condensed-water features in the simultaneously recorded infrared extinction spectra, shown in the top left panel of Fig. 4. The liquid water extinction bands are located at about $3300 \mathrm{~cm}^{-1}(\mathrm{O}-\mathrm{H}$ stretching mode) and $1640 \mathrm{~cm}^{-1}$ (H-O-H bending mode). Similar to the IR spectroscopic study on the efflorescence of $\mathrm{NaCl}$ by Cziczo and Abbatt (2000), anhydrous crystals of sodium chloride have formed instead of $\mathrm{NaCl} \cdot 2 \mathrm{H}_{2} \mathrm{O}$ that is the stable crystalline solid below the $\mathrm{NaCl} / \mathrm{NaCl} \cdot 2 \mathrm{H}_{2} \mathrm{O}$ peritectic temperature of 273.3 K (Koop et al., 2000). The latter species can be unambiguously identified by its prominent, highly structured infrared spectrum in the regime of the $\mathrm{O}-\mathrm{H}$ stretching mode due to the hydration water (Schiffer and Hornig, 1961). We will discuss this issue in more detail in Sect. 4.1.2.

The observation of $\mathrm{NaCl}$ efflorescence at a comparatively high relative humidity of $70 \%$ is in contrast to a set of literature studies that have reported an efflorescence relative humidity of about $45 \%$, see Table 1 in Gao et al. (2007). We have recently observed a similar discrepancy for the efflorescence behaviour of oxalic acid. Whereas several previous studies have reported on the difficulty to effloresce oxalic acid particles even at very low relative humidities of less than 5\% (Braban et al., 2003; Mikhailov et al., 2009; Prenni et al., 2001), supercooled aqueous oxalic acid solution droplets readily crystallised in AIDA at $244 \mathrm{~K}$ and $70 \% \mathrm{RH}$ on a time scale of about one hour (Wagner et al., 2010). As outlined in our recent work, we will attempt to quantitatively analyse the crystallisation process in future chamber studies by exploiting the potential of a novel light scattering instrument (Small Ice Detector probe SID3, University of Hertfordshire) to determine the crystallisation rate. At present, we cannot completely exclude that the observed high efflorescence relative humidity might be due to chamber-related artefacts, e.g. collision-induced crystallisation by the rotors of the mixing fan. Also, the aerosol particles will temporarily concentrate and might crystallise when passing regimes of lower relative humidity inside the chamber close to heat sources like heated sampling tubes and the heated mirrors of the internal multiple reflection cells (see Sect. 3.1). Such crystallised particles could then further instigate the crystallisation of still liquid, supersaturated $\mathrm{NaCl}$ solution droplets.

After an observation time of about $4 \mathrm{~h}$, the major part of the volume fraction of the injected $\mathrm{NaCl} / \mathrm{H}_{2} \mathrm{O}$ solution droplets had crystallised and the generated solid $\mathrm{NaCl}$ particles were probed on their hygroscopic behaviour and ice nucleability in an expansion cooling experiment at $244 \mathrm{~K}$ (Fig. 5, left panel). The AIDA records from the cooling cycle are arranged in the following order. In the top row panel, the time evolution of the AIDA pressure (black line) and the mean AIDA gas temperature (red line) are shown. The second row depicts time series of the saturation ratios with respect to ice ( $S_{\text {ice }}$, black line) and supercooled water $\left(S_{\text {liq }}\right.$, red line) from the TDL water vapour absorption measurements. As a comparison, the trace for $S_{\text {ice }}$ that was calculated for the ex situ measured total water concentration is shown as blue line. In the absence of any clouds of supercooled water droplets and/or ice crystals and provided that any aerosol water content, if present, can be neglected in comparison with the interstitial water vapour concentration, both traces for $S_{\text {ice }}$ coincide. In the third row panel, the scatter plot from the OPC2 is shown where each dot represents a single particle count event that was classified into one of the OPC2 size channels. Whereas the size of spherical particles of known refractive index is exactly determined, the size information for aspherical particles is ambiguous due to the dependence of the phase function on the particle shape and orientation in the detection volume. Both employed OPCs detect the pulses of white light that was scattered by single particles at side-scattering angles from $78-102^{\circ}$ and correlate the measured scattering intensity with the particle diameter assuming Mie theory. In the side-scattering regime, the values of the normalised phase function for aspherical particle habits are usually higher than those for equivalent spheres whose phase function features a prominent minimum in this regime (Liu et al., 2006). For this reason, the size of aspherical particles is typically overestimated in the OPC scatter plots by up to a factor of two. A population of deliquesced $\mathrm{NaCl}$ solution droplets will therefore be classified by the OPC2 at smaller diameters than an ensemble of crystalline $\mathrm{NaCl}$ particles. Large aspherical ice particles that have nucleated in AIDA during an expansion cooling cycle can be distinguished from small interstitial aerosol particles and/or cloud droplets by introducing an optical threshold size. Adding all particle count events above that threshold size yields the ice particle number concentration $N_{\text {ice }}$. The ice-active number 

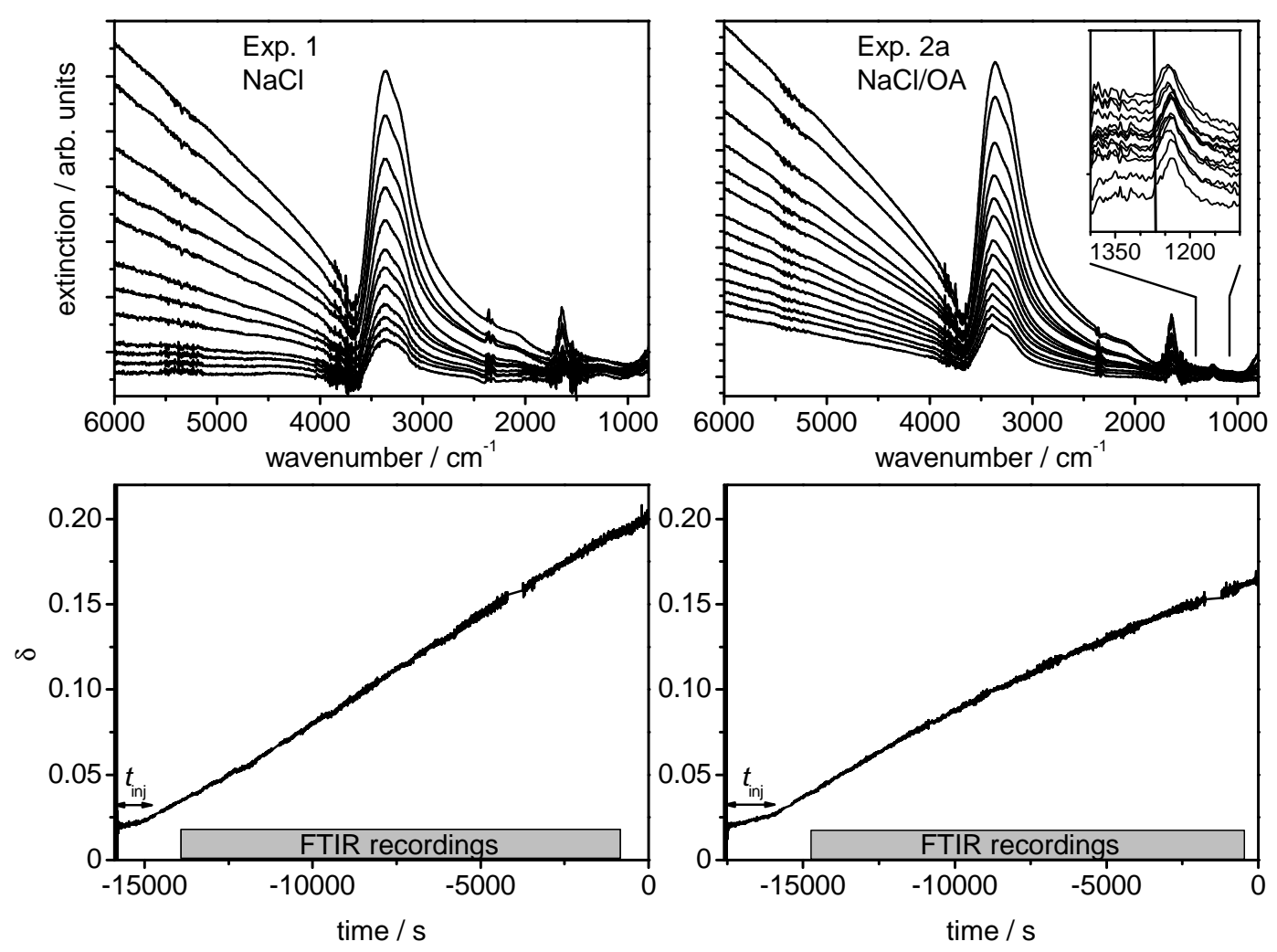

Fig. 4. Bottom panels: Time series of the backscattering linear depolarisation ratio $\delta$ after spraying aqueous solutions of $5 \mathrm{wt} \% \mathrm{NaCl}$ (Exp. 1 , Table 1, left panel) and $5 \mathrm{wt} \% \mathrm{NaCl}+0.51 \mathrm{wt} \% \mathrm{OA}$ (Exp. 2a, right panel) into the AIDA chamber at $244 \mathrm{~K}$ with an ultrasonic nebuliser. The horizontal arrows denote the overall time period of aerosol injection $\left(t_{\text {inj }}\right)$. Time zero denotes the start of the first expansion cooling cycles that were performed later on to study the ice nucleability of the crystallised particles. The horizontal grey bars on the time scales denote the time periods of the FTIR spectra recordings that are shown in the top panels. The spectra are to be read from top to bottom and were recorded at a time interval of $20 \mathrm{~min}$. The inset in the top right panel shows an enlarged view in the regime of the $\mathrm{C}-\mathrm{O}$ stretching mode of oxalic acid.

fraction $f_{\text {ice }}$ of the aerosol population, obtained by further dividing $N_{\text {ice }}$ through the prevailing aerosol number concentration, is shown in the fourth row panel of Fig. 5. The bottom panel contains time series of the two records $I_{\text {back,par }}$ (black line) and $\delta$ (red line) from the laser light scattering and depolarisation measurements.

Shortly after the onset of pumping at time zero, when surpassing a relative humidity ( $\left.S_{\mathrm{liq}}\right)$ of $(72 \pm 3) \%$, the depolarisation ratio $\delta$ drops to its background value of 0.02 , indicating the deliquescence transition of the $\mathrm{NaCl}$ crystals to form saturated aqueous solution droplets. The sudden water uptake leads to an increase in the size of the particles which manifests itself in a stepwise increase in the backscattered intensity $I_{\text {back,par. }}$ In contrast, for the reason outlined above, the deliquesced solution droplets are counted by the OPC2 at smaller diameters than the effloresced $\mathrm{NaCl}$ crystals. Note that the OPC2 only records the largest particles of the entire $\mathrm{NaCl}$ aerosol size distribution (see left panel of Fig. 3) whereas micron-sized cloud droplets and ice crystals are quantitatively counted. The observed deliquescence relative humidity agrees with low-temperature deliquescence measurements for $\mathrm{NaCl}$ in a flow cell apparatus and falls onto the extrapolated line for anhydrous $\mathrm{NaCl}$ to low temperatures, indicating that indeed $\mathrm{NaCl}$ has formed upon efflorescence instead of $\mathrm{NaCl} \cdot 2 \mathrm{H}_{2} \mathrm{O}$ (Koop et al., 2000). Upon further expansion cooling, the deliquesced $\mathrm{NaCl}$ solution droplets further grow by the uptake of water vapour from the gas phase, as can be seen by the continuous increase in $I_{\text {back,par }}$ after the deliquescence step. When exceeding saturation with respect to supercooled water at about $t=70 \mathrm{~s}$ (first vertical green line), the seed aerosol particles are activated to a droplet cloud that rapidly grows into the size range of the OPC2 and is evident as a dense point cloud with diameters of up to $10 \mu \mathrm{m}$. The droplet cloud is maintained for a very long time period in AIDA until at $t=240 \mathrm{~s}$ (second green line) the gas temperature has further dropped below the homogeneous freezing temperature of pure water droplets during the continued expansion. The subsequent glaciation of the droplet cloud provokes an increase of the depolarisation ratio and a decrease of the relative humidity to $S_{\text {ice }}=1$. The scatter signals of the nucleated ice crystals appear as a point cloud at very large diameters in the OPC2 scatter plot. Before 

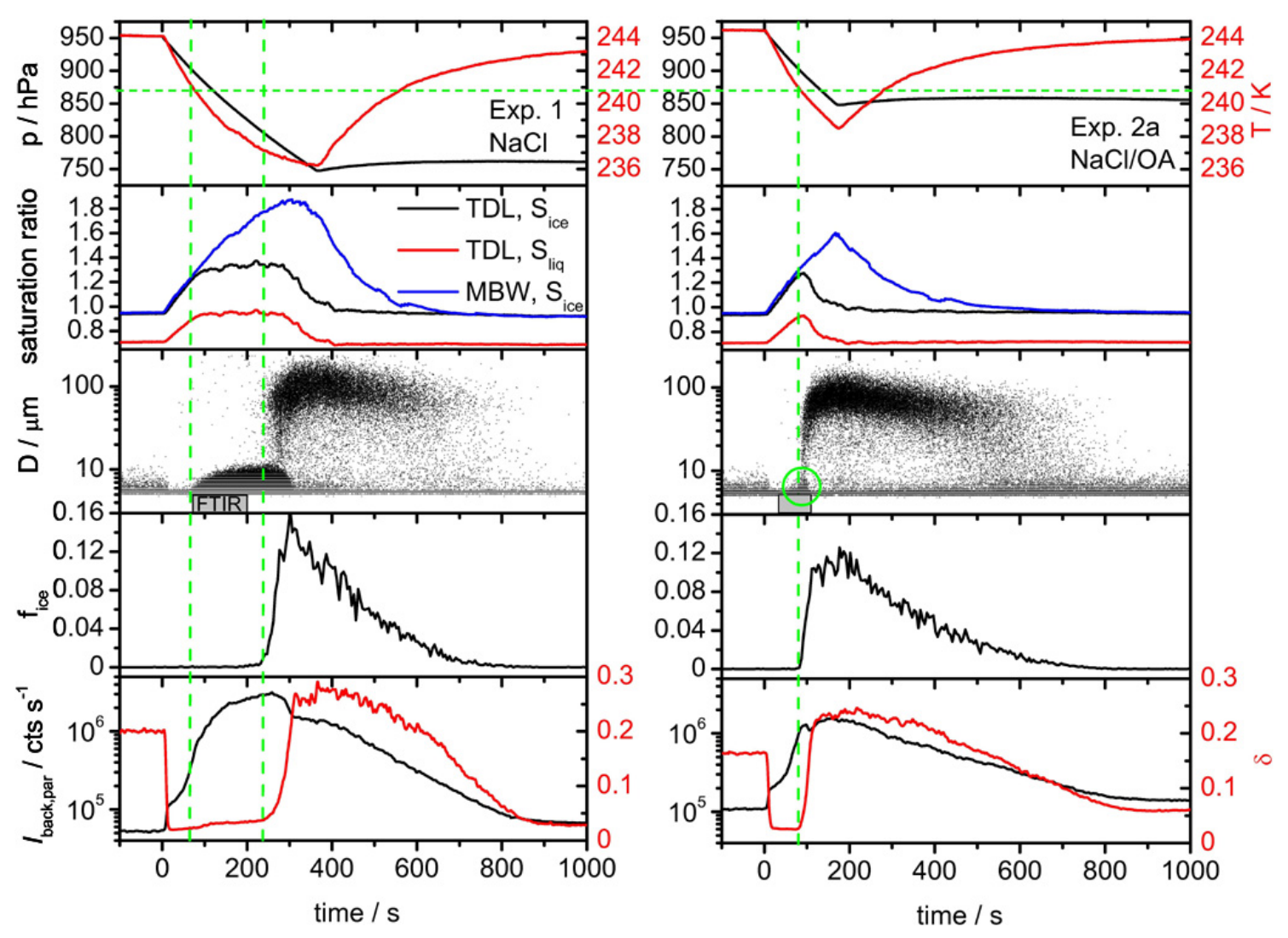

Fig. 5. Time series of various AIDA records during the first expansion cooling cycles from Exp. 1 and Exp. 2a that were started at $244 \mathrm{~K}$. In each graph, time zero denotes the start of pumping (see Fig. 4). The five panels contain the following data. Panel 1: AIDA pressure (black line) and mean gas temperature (red line). Panel 2: Saturation ratios with respect to ice ( $S_{\text {ice}}$, black and blue line) and supercooled water ( $S_{\text {liq }}$, red line). $S_{\text {liq }}$ is only shown for the gas-phase water concentration measured by TDL absorption whereas $S_{\text {ice }}$ is plotted for both the gas-phase and total water concentration as measured ex situ with the MBW chilled mirror hygrometer. Panel 3: Size of individual particles detected by the OPC2. The horizontal grey bars denote the time periods of the FTIR spectra recordings that are shown in Fig. 8. Panel 4: Number fraction of ice-active aerosol particles. Panel 5: Backscattering intensity parallel to the incident polarisation state of the laser light (black line) and backscattering linear depolarisation ratio $\delta$ (red line). All y-axes in adjacent sub-panels are identically scaled to facilitate the comparison of the records from Exp. 1 and Exp. 2a. See text for details.

$t=240 \mathrm{~s}$, only very few large ice crystals with a number concentration of less than $0.1 \mathrm{~cm}^{-3}$ are detected by the OPC2, probably formed by nucleation on the small number of background aerosol particles that were present in the chamber. After the stop of expansion cooling at $t=370 \mathrm{~s}$, the ice crystals evaporate on a time scale of about $400 \mathrm{~s}$. The largest particles may also be lost by sedimentation.

After the evaporation of the ice cloud, the AIDA chamber was slowly cooled to $235 \mathrm{~K}$ over a time period of $3 \mathrm{~h}$ and another expansion cooling cycle with the same aerosol load was started as shown in the left panel of Fig. 7. At the end of the first expansion cooling cycle $(t=1000 \mathrm{~s}$, Fig. 5), the depolarisation ratio $\delta$ had again temporarily returned to the background value that was monitored at the beginning of aerosol injection as well as immediately after the deliquescence transition in the early stage of the expansion experiment. While cooling the AIDA chamber to $235 \mathrm{~K}$, however, the deliquesced $\mathrm{NaCl}$ solution droplets again crystallised, leading to an increase of $\delta$ to 0.26 before the second expansion cooling cycle was started, as shown in Fig. 6. In the following discussion, we will refer to this time period as the second crystallisation period whereas the time period of crystallisation immediately after aerosol injection will be called the first crystallisation period. During the second expansion run, the $\mathrm{NaCl}$ crystals again deliquesce at $\mathrm{RH}=(72 \pm 3) \%$ (for the sake of clarity, as explained in the caption of Fig. 7, the trace for $S_{\text {liq }}$ is not shown). The generated supercooled solution droplets further take up water until $t=130 \mathrm{~s}$ where their critical dilution has been surpassed and homogeneous freezing occurs at $S_{\text {ice }}=1.38$ and $T=231 \mathrm{~K}$. The nucleated ice crystals rapidly deplete the excess of water vapour from the gas phase, thereby limiting the maximum of the ice saturation ratio, $S_{\text {ice, max }}$, to a value of 1.40. Due to the lower AIDA temperature in the second expansion cooling cycle, the 


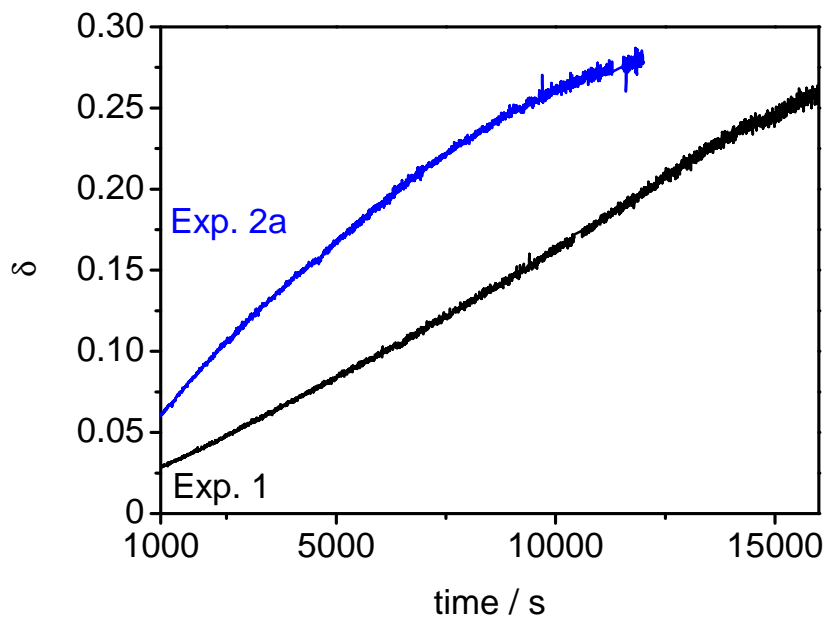

Fig. 6. Time series of the backscattering linear depolarisation ratio, $\delta$ from Exp. 1 (black line) and Exp. 2a (blue line), recorded during the second crystallisation periods after the end of the first expansion cooling cycles (Fig. 5) while cooling the AIDA chamber to $235 \mathrm{~K}$. The records end with the start of the second expansion cooling cycles which are shown in Fig. 7.

chamber air was already slightly supersaturated with respect to ice before the deliquescence transition of $\mathrm{NaCl}$ had occurred. The solid $\mathrm{NaCl}$ crystals, however, are not ice-active in the deposition mode at low ice supersaturations because early ice formation was not detected. This is the prerequisite for the experiments in the ternary $\mathrm{NaCl} / \mathrm{OA} / \mathrm{H}_{2} \mathrm{O}$ system on the immersion freezing potential of oxalic acid that will be discussed in the following sections. When performing expansion cooling cycles with mixed effloresced $\mathrm{NaCl} / \mathrm{OA}$ particles, the surrounding salt matrix will not be active as a heterogeneous ice nucleus but will undergo deliquescence to form aqueous $\mathrm{NaCl}$ solution droplets with embedded $\mathrm{OA}$ crystallites whose immersion freezing potential can then be investigated.

\subsubsection{Detailed analysis of the ternary $\mathrm{NaCl} / \mathrm{OA} / \mathrm{H}_{2} \mathrm{O}$ ice nucleation experiments $2 \mathrm{a}$ and $2 \mathrm{~b}$}

The right panels of Figs. 4, 5, and 7 are duplicates of their left-hand counterparts for an experiment where, instead of a binary $5 \mathrm{wt} \% \mathrm{NaCl}$ solution, a ternary solution with $5 \mathrm{wt} \%$ $\mathrm{NaCl}$ and $0.51 \mathrm{wt} \%$ OA was sprayed into the AIDA chamber at $244 \mathrm{~K}$ and $70 \% \mathrm{RH}$ (Exp. 2a in Table 1). As the solubility of $\mathrm{OA}$ is significantly decreased in $\mathrm{NaCl}$ solutions compared to pure water, this solution was almost saturated with OA at room temperature.

As shown in the right panels of Fig. 4, the ensemble of injected ternary solution droplets continuously crystallised on a time scale of several hours, similarly to the binary $\mathrm{NaCl} / \mathrm{H}_{2} \mathrm{O}$ system from Exp. 1. The enlarged frame in the panel with the FTIR spectra recordings shows the subset in the regime of the $\mathrm{C}-\mathrm{O}$ stretching mode of oxalic acid. The vertical line indicates the peak position of this transition in pure oxalic acid dihydrate crystals at around $1270 \mathrm{~cm}^{-1}$. Interestingly, the observed band position does not shift from its original location of $1240 \mathrm{~cm}^{-1}$ (characteristic of aqueous oxalic acid) to $1270 \mathrm{~cm}^{-1}$ during crystallisation. The results from the expansion cooling cycles will clearly evidence that mixed effloresced particles of sodium chloride and oxalic acid crystals have formed. So either the surrounding $\mathrm{NaCl}$ matrix strongly effects the peak position of the $\mathrm{C}-\mathrm{O}$ vibrational mode in oxalic acid dihydrate or a different species has formed, e.g. anhydrous $\beta$ oxalic acid crystals whose $\mathrm{C}-\mathrm{O}$ stretching mode is slightly shifted to lower wavenumbers compared to oxalic acid dihydrate and thus approximately overlaps with the band position in aqueous oxalic acid (Bellamy and Pace, 1963; Braban et al., 2003). Upon starting the first expansion cooling cycle at $244 \mathrm{~K}$ (Fig. 5, right panel), the internally mixed $\mathrm{NaCl} / \mathrm{OA}$ particles undergo a deliquescence transition at $(72 \pm 3) \% \mathrm{RH}$, i.e., the deliquescence behaviour of $\mathrm{NaCl}$ remains unchanged in the mixture with oxalic acid. Such behaviour has been typically observed for mixtures of inorganics and slightly water soluble dicarboxylic acids, such as mixtures of ammonium sulphate and oxalic, succinic, or adipic acid (Brooks et al., 2002), mixtures of succinic acid and sodium chloride (Choi and Chan, 2002) or ammonium nitrate (Lightstone et al., 2000), as well as for mixtures of oxalic or succinic acid and a five-component combination of high water-soluble dicarboxylic acids (Marcolli et al., 2004). At the deliquescence point, the inorganic fraction (or the mixture of high water-soluble dicarboxylic acids) forms a droplet, containing only a minor weight fraction of the less water soluble organic acid that gets dissolved according to the eutonic composition. The remaining part of the slightly water soluble organic compound forms a solid inclusion within the droplet. Evidence for such solid, non-spherical inclusion has been provided by light scattering measurements on mixed particles of ammonium nitrate/succinic acid ( $25 \%$ succinic acid by mass) that were levitated in an electrodynamic balance (Lightstone et al., 2000). Also at elevated humidity levels well above the deliquescence point of ammonium nitrate, the recorded light scattering signal still contained the random high-frequency signal characteristic of solid, nonspherical particles; see Fig. 5 in Lightstone et al. (2000).

Concerning the internally mixed $\mathrm{NaCl} / \mathrm{OA}$ particles with only $10 \%$ OA by mass from Exp. 2a, the sizes of the embedded oxalic acid crystals that remain undissolved after the deliquescence of $\mathrm{NaCl}$ are too small to provoke any change in the depolarisation ratio in relation to the background value of 0.02 for completely liquid droplets that was observed after the deliquescence transition in Exp. 1. The solid OA inclusions, however, significantly affect the ice nucleability of the solution droplets. Almost immediately after the seed aerosol particles have become activated into cloud droplets at water saturation $(t=75 \mathrm{~s}$, vertical green line), the droplet cloud glaciates at a temperature of $241 \mathrm{~K}$, i.e., well above the 

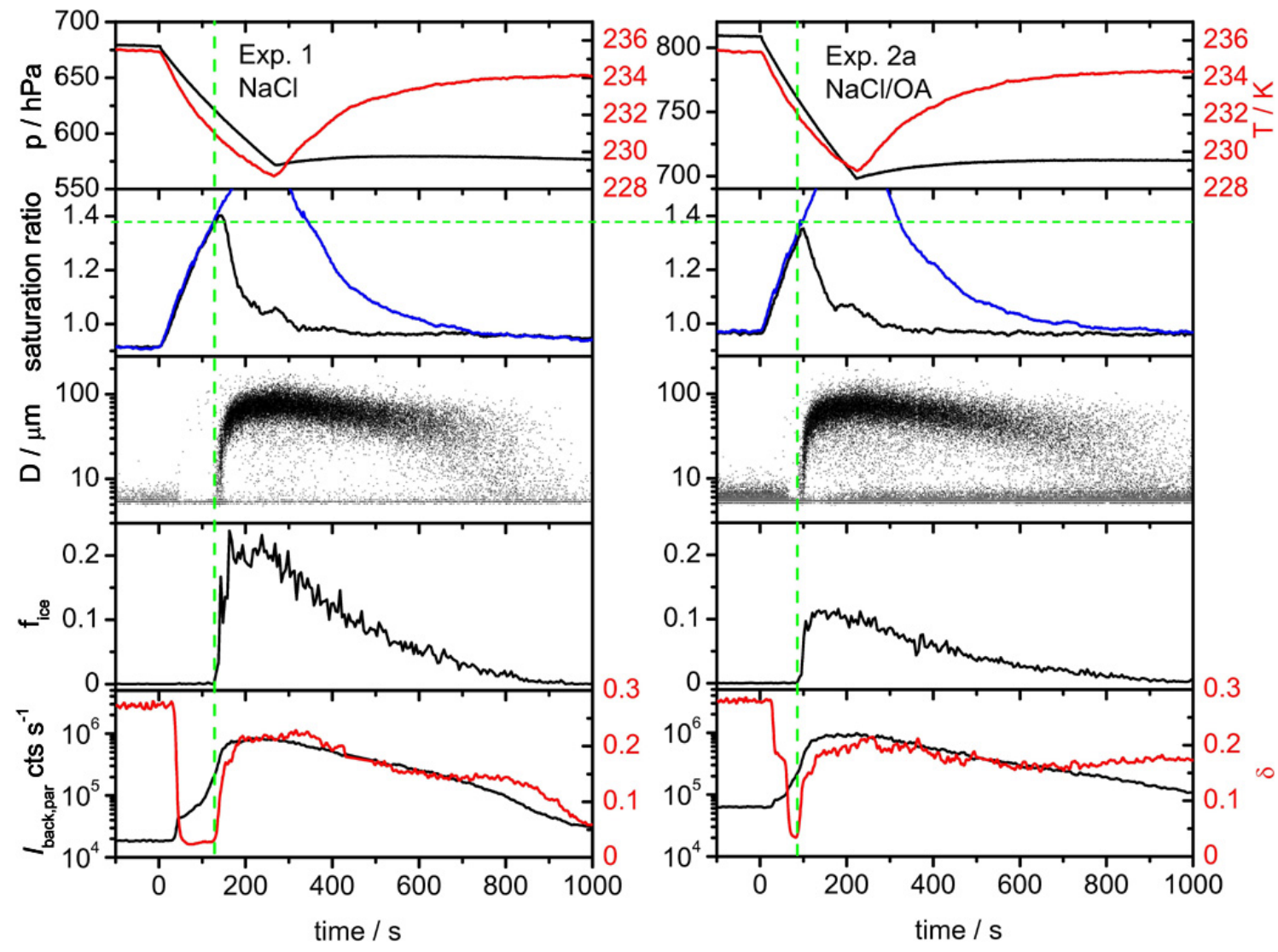

Fig. 7. Time series of various AIDA records during the second expansion cooling cycles from Exp. 1 and Exp. 2a that were started at $235 \mathrm{~K}$. Time zero again denotes the start of pumping and corresponds to the time stamp of the last records in the respective time series of the depolarisation ratio that are shown in Fig. 6. The individual panels contain the same measurements as in Fig. 5. In order to elucidate the subtle differences in the critical ice saturation ratio between the two experiments, the traces for $S_{\text {liq }}$ are omitted to show the recorded ice saturation ratios on an enlarged y-axis scale in the second row panels. Except for the top-row panels, all y-axes of adjacent panels are identically scaled.

homogeneous freezing temperature of pure water droplets at which ice nucleation has started in Exp. 1. Note that the cloud droplets in Exp. 2a have barely grown into the measurement range of the OPC2 (as highlighted by the green circle in the scatter plot) before the ice cloud is formed whereas the droplet cloud in Exp. 1 persists for a much longer time period so that the water droplets can grow to much larger diameters during expansion cooling. This behaviour is further illustrated by the two series of FTIR spectra recordings that are shown in Fig. 8. The spectra are arranged from bottom to top and were recorded at a rate of 6 spectra $\min ^{-1}$ during the time periods that are indicated as grey horizontal bars on the time scales of the OPC2 scatter plots in Fig. 5. The first six spectra recordings from Exp. 2a reflect the water uptake and droplet activation of the $\mathrm{NaCl} / \mathrm{OA}$ particles after the deliquescence transition, as evidenced by the growth of the liquid water extinction band at $3300 \mathrm{~cm}^{-1}$. The signature of the sixth spectrum can be accurately reproduced with a Mie fit using the optical constants of supercooled water (blue line), yielding a median droplet diameter of $2.0 \mu \mathrm{m}$ (Zasetsky et al.,
2005). Twenty seconds later, the recorded infrared spectrum already bears the signature of a mixed phase cloud. Superimposed on the liquid water extinction bands are two pronounced extinction minima at 3500 and $950 \mathrm{~cm}^{-1}$, the socalled Christiansen bands of large ice crystals (Arnott et al., 1995). The spectrum can only be accurately mimicked by a bimodal fit (red line), with one mode of $2.7 \mu$ m median diameter for water droplets and a second mode of $10 \mu \mathrm{m}$ median (equal-volume sphere) diameter for ice crystals. Another ten seconds later, the extinction features due to liquid water have almost disappeared and a pure ice cloud has remained. In contrast, the spectral signatures of cloud droplets can be monitored for a much longer time period during Exp. 1. The spectra series displays the growth of the cloud droplets during expansion cooling, starting with a median diameter of $1.9 \mu \mathrm{m}$ (blue line, Mie fit of the lowermost spectrum) and ending with a diameter of $6.5 \mu \mathrm{m}$ (red line, Mie fit of the uppermost spectrum) prior to glaciation at the homogeneous freezing temperature. 

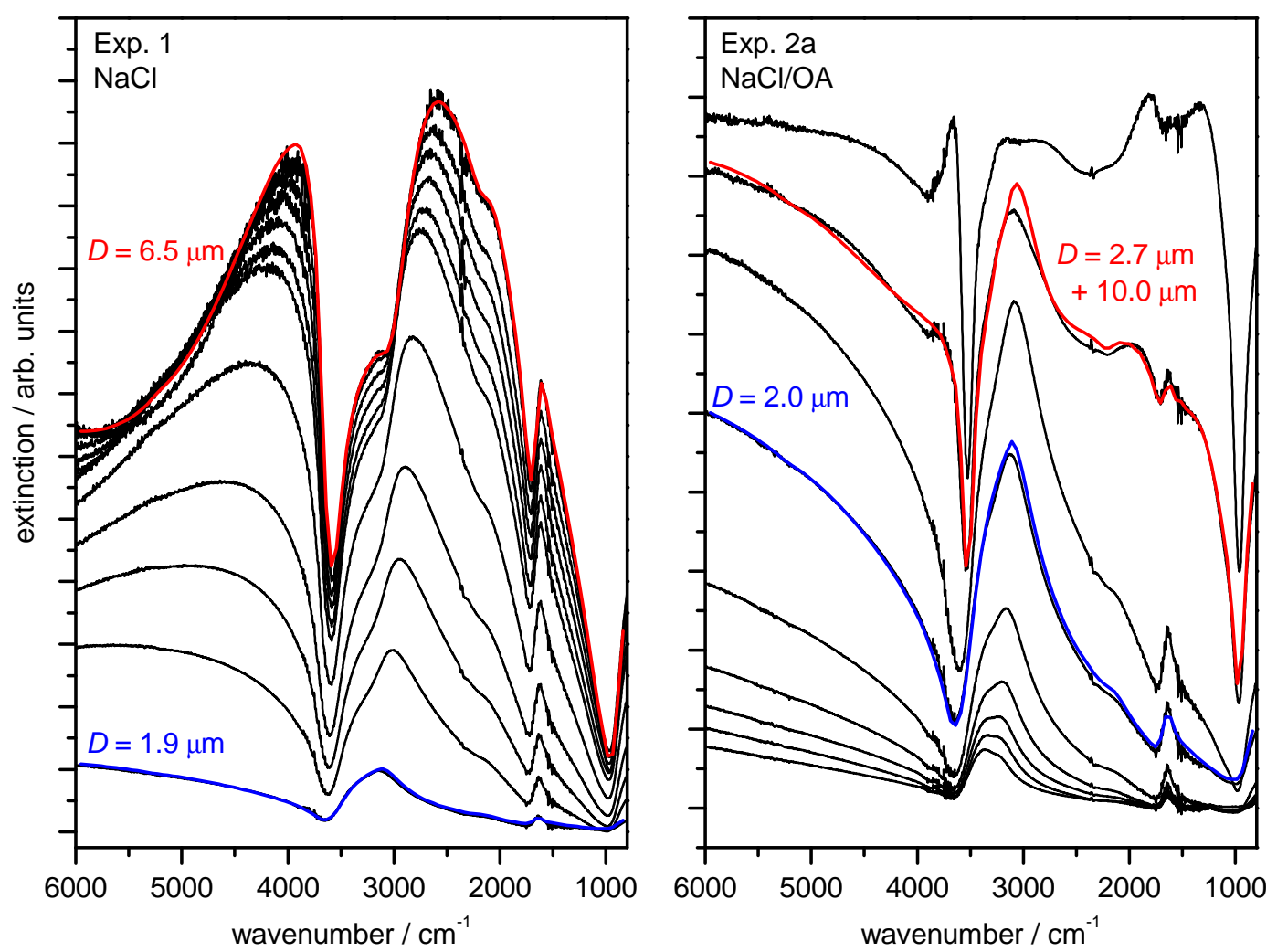

Fig. 8. Series of infrared extinction spectra recorded during the first expansion cooling cycles of Exp. 1 and Exp. 2a (black lines). The spectra are to be read from bottom to top and were recorded at a $10 \mathrm{~s}$ time interval during $t=70-200 \mathrm{~s}$ (Exp. 1) and $t=30-110 \mathrm{~s}($ Exp. $2 \mathrm{a}$ ), as indicated by horizontal grey bars on the time scales of the OPC2 scatter plots in Fig. 5. Various computed extinction spectra that best-fitted the measurements are shown as red and blue lines. Both coloured lines in the left panel as well as the blue trace in the right panel represent fits by unimodal log-normal number size distributions of supercooled water, yielding the indicated count median diameters $D$. The red line in the right panel represents a bimodal fit by two log-normal modes, with one mode for water droplets and the other for ice crystals. The latter were modelled as circular cylinders of aspect ratio 0.7 (Wagner et al., 2006a).

The comparison of the AIDA records from Exp. 1 and Exp. 2a underlines that the embedded OA crystals act as very efficient heterogeneous ice nuclei in the condensation mode. A significant number fraction, $f_{\text {ice, }}$, of about $10 \%$ of the overall aerosol population has formed ice in the expansion cooling cycle. Due to the large number of nucleated ice crystals, the relative humidity quickly drops below $100 \%$, i.e., the supersaturation with respect to ice is depleted. The increasing sub-saturation with respect to supercooled water causes the remaining cloud droplets to evaporate and to transform into interstitial $\mathrm{NaCl} / \mathrm{OA} / \mathrm{H}_{2} \mathrm{O}$ aerosol particles again. In that way, immersed OA particles with a slightly lower ice activity will be prevented from contributing to $f_{\text {ice }}$. Obviously, the OA inclusions do not get instantly and completely dissolved during CCN activation and subsequent droplet growth but can trigger the glaciation of the droplet cloud at a temperature much higher than monitored in Exp. 1. Such incomplete dissolution of oxalic acid has also been observed in our previous study; see e.g. Fig. 14 in Wagner et al. (2010) and the related discussion. Note that during Exp. 2a pumping was stopped shortly after the droplet cloud had glaciated and $S_{\text {ice }}$ had levelled off at a value of one. Thereby, the gas temperature had always been well above the freezing temperature from Exp. 1.

In the same way as in Exp. 1, the AIDA chamber was slowly cooled to $235 \mathrm{~K}$ after the ice cloud from the first expansion cooling cycle of Exp. 2a had evaporated. The depolarisation ratio $\delta$ had not completely levelled off at the background value of 0.02 after the evaporation of the ice cloud, indicating that a fraction of the $\mathrm{NaCl} / \mathrm{OA} / \mathrm{H}_{2} \mathrm{O}$ aerosol population had already started to effloresce. As discussed below, the crystallisation of the particle ensemble in the second crystallisation period might be facilitated by the immersed OA crystals that have remained as solid particulates within the solution droplets. During cooling, $\delta$ increased to a value of 0.28 (Fig. 6). The AIDA records from the second expansion cooling cycle (Fig. 7, right panel) reveal two pronounced differences compared to Exp. 1. Firstly, the ensemble of $\mathrm{NaCl} / \mathrm{OA}$ particles undergoes a dual deliquescence transition at 72 and $82 \% \mathrm{RH}$, as nicely documented by the 
two-step decrease in the depolarisation ratio. Secondly, the $\mathrm{OA}$ crystals that remain immersed in the aqueous $\mathrm{NaCl}$ solution droplets upon deliquescence induce earlier ice formation in comparison with the homogeneous freezing run from Exp. 1. The critical ice saturation ratio, $S_{\text {ice, crit, }}$ is reduced from 1.38 to 1.32 , thereby provoking that during Exp. 2a the peak relative humidity stays below the homogeneous freezing threshold from Exp. 1, as indicated by the horizontal green line. Similarly to the first expansion run at $244 \mathrm{~K}, f_{\text {ice }}$ amounts to about $10 \%$. Our results thereby confirm the findings from Zobrist et al. (2006) that oxalic acid acts a heterogeneous ice nucleus. A detailed comparison with the Zobrist et al. (2006) results is given in Sect. 4.1.4 after the discussion of Exps. 2b, 3, 4, and 5. We now focus on the deliquescence behaviour of the mixed $\mathrm{NaCl} / \mathrm{OA}$ particles.

The additionally observed deliquescence transition at $82 \%$ $\mathrm{RH}$ approximately falls onto the expected deliquescence curve of $\mathrm{NaCl} \cdot 2 \mathrm{H}_{2} \mathrm{O}$, as constructed in the temperature $\mathrm{RH}$ plane of the $\mathrm{NaCl}-\mathrm{H}_{2} \mathrm{O}$ phase diagram by connecting the deliquescence relative humidity line of $\mathrm{NaCl}$ at the $\mathrm{NaCl} / \mathrm{NaCl} \cdot 2 \mathrm{H}_{2} \mathrm{O}$ peritectic temperature of $273.3 \mathrm{~K}$ to the ice melting point curve at the ice $/ \mathrm{NaCl} \cdot 2 \mathrm{H}_{2} \mathrm{O}$ eutectic temperature of 251.9 K; see Fig. 6 in Koop et al. (2000). Therefore, the aerosol population before the second cooling cycle in Exp. 2a has consisted of an external mixture containing both $\mathrm{NaCl} / \mathrm{OA}$ as well as $\mathrm{NaCl} \cdot 2 \mathrm{H}_{2} \mathrm{O} / \mathrm{OA}$ crystals. Note that prior to the second crystallisation period of Exp. 2a after performing the expansion cooling cycle at $244 \mathrm{~K}$, the salt solution droplets already contained a solid nucleus of oxalic acid because, as discussed above, the oxalic acid crystals did not get completely dissolved on the timescale of the expansion cooling experiment. In contrast, both the first and second crystallisation periods of Exp. 1 and the first crystallisation period of Exp. 2a have involved entirely liquid solution droplets. As evident from Fig. 6, the rate of increase of the depolarisation ratio $\delta$ during the second crystallisation period of Exp. 2a was significantly higher than during the respective crystallisation period of Exp. 1, indicating that a different, more efficient crystallisation mechanism was involved. We therefore speculate that the partial formation of $\mathrm{NaCl} \cdot 2 \mathrm{H}_{2} \mathrm{O} / \mathrm{OA}$ particles in the second crystallisation period of Exp. 2a was induced by heterogeneous nucleation on the surface of the embedded oxalic acid crystals. On the contrary, homogeneous crystallisation obviously leads to the formation of anhydrous sodium chloride.

That heterogeneous crystallisation favours the formation of $\mathrm{NaCl} \cdot 2 \mathrm{H}_{2} \mathrm{O}$ is in agreement with observations from Koop et al. (2000). Whereas $\mathrm{NaCl} \cdot 2 \mathrm{H}_{2} \mathrm{O}$ did not form in their flow cell efflorescence experiments (homogeneous crystallisation), the precipitation of ice and $\mathrm{NaCl} \cdot 2 \mathrm{H}_{2} \mathrm{O}$ was detected in additional freezing and melting experiments with bulk and emulsion samples of aqueous $\mathrm{NaCl}$. Individual freezing peaks for ice and $\mathrm{NaCl} \cdot 2 \mathrm{H}_{2} \mathrm{O}$ were detected for low $\mathrm{NaCl}$ concentrations whereas above threshold concentrations of $10 \mathrm{wt} \% \mathrm{NaCl}$ (emulsion samples) or $16 \mathrm{wt} \% \mathrm{NaCl}$ (bulk samples), single freezing peaks were detected in the cooling experiments, indicating that $\mathrm{NaCl} \cdot 2 \mathrm{H}_{2} \mathrm{O}$ instantly formed upon ice nucleation, probably induced by heterogeneous nucleation on the ice crystal surface. In our experiments, it is not the ice particle surface but the surface of the immersed OA crystals that most likely triggers the precipitation of $\mathrm{NaCl} \cdot 2 \mathrm{H}_{2} \mathrm{O}$ within a certain number fraction of the $\mathrm{NaCl} / \mathrm{OA} / \mathrm{H}_{2} \mathrm{O}$ aerosol particles. Instantaneous crystallisation of $\mathrm{NaCl} \cdot 2 \mathrm{H}_{2} \mathrm{O}$ triggered by ice formation, as discovered by Koop et al. (2000) in the experiments with bulk and emulsion samples, is difficult to detect in our expansion experiments and should have also been observed during ice cloud formation in Exp. 1 with binary $\mathrm{NaCl} / \mathrm{H}_{2} \mathrm{O}$ solution droplets. If immediate, ice-mediated crystallisation of $\mathrm{NaCl} \cdot 2 \mathrm{H}_{2} \mathrm{O}$ had occurred in all aerosol particles that have nucleated ice in the first expansion run of Exp. 1, the overall aerosol population would already have contained a $10 \%$ number fraction of crystalline particles directly after the ice cloud had evaporated. If so, the depolarisation ratio would not have returned to its background value of 0.02 after ice cloud formation and evaporation in this expansion cooling cycle (Fig. 5, left panel). Obviously, the crystallisation efficiency of freeze-concentrated $\mathrm{NaCl}$ solutions in contact with ice particles to form $\mathrm{NaCl} \cdot 2 \mathrm{H}_{2} \mathrm{O}$ particles is much lower in our experiments, meaning that the number fraction of particles that have actually crystallised via this process is too low to provoke a significant increase in the depolarisation ratio. We have discussed this issue in such detail because it closely relates to the experiments that are presented in Sect. 4.2 where we want to study the efficiency of the ice surface mediated precipitation of oxalic acid dihydrate from ternary $\mathrm{H}_{2} \mathrm{SO}_{4} / \mathrm{OA} / \mathrm{H}_{2} \mathrm{O}$ solutions. The different observations for the efficiency of $\mathrm{NaCl} \cdot 2 \mathrm{H}_{2} \mathrm{O}$ formation by heterogeneous crystallisation on ice in either freezing experiments with emulsion samples (Koop et al., 2000) or ice nucleation experiments with airborne particles (AIDA) already support our comments from Sect. 2.2 that it will be difficult to replicate the findings from the Zobrist et al. (2006) emulsion freezing experiments in AIDA expansion cooling cycles.

With the procedure of Exp. 2a, we could only indirectly prove the precipitation of $\mathrm{NaCl} \cdot 2 \mathrm{H}_{2} \mathrm{O} / \mathrm{OA}$ in the second crystallisation period by the observation of the second deliquescence step at $82 \% \mathrm{RH}$. Independent evidence from the FTIR spectra recordings was not available because the cooling of the AIDA chamber to $235 \mathrm{~K}$ induced a slight misalignment of the optical set-up and the initially recorded background spectrum was no longer a suited reference. In Exp. $2 b$, performed with a fresh aerosol loading, we have therefore slightly modified the experimental procedure as follows. After the first expansion cooling cycle at $244 \mathrm{~K}$ (whose AIDA records closely reproduced the data shown in the right panel of Fig. 5), the chamber was not cooled to $235 \mathrm{~K}$ but its temperature was kept constant at $244 \mathrm{~K}$ during the second crystallisation period to probe the chemical nature of the crystallised particles by FTIR extinction spectroscopy. 
The recorded infrared spectrum is shown as trace b in Fig. 9 and indeed bears the prominent signatures of sodium chloride dihydrate, as can be seen by the comparison with the reference spectra of $\mathrm{NaCl} \cdot 2 \mathrm{H}_{2} \mathrm{O}$ in the regime of the $\mathrm{O}-\mathrm{H}$ stretching (trace a1) and $\mathrm{H}-\mathrm{O}-\mathrm{H}$ bending mode (trace a2) that were obtained by digitising Fig. 1 from Schiffer and Hornig (1961). The second expansion cooling cycle in Exp. 2b, thereafter performed at $244 \mathrm{~K}$, indeed featured a dual deliquescence transition at $72 \%$ and $82 \% \mathrm{RH}$ due to $\mathrm{NaCl}$ (invisible in the FTIR spectrum) and $\mathrm{NaCl} \cdot 2 \mathrm{H}_{2} \mathrm{O}$, respectively. Additionally shown in Fig. 9 are the infrared extinction spectrum of bare oxalic acid dihydrate crystals (trace d) from our previous work (Wagner et al., 2010) as well as the final spectrum from the first crystallisation period of Exp. 2a (trace $\mathrm{c}$, lowermost spectrum from the series shown in the right panel of Fig. 4). As already discussed in the context of Fig. 4, the position of the $\mathrm{C}-\mathrm{O}$ stretching mode of oxalic acid at $1240 \mathrm{~cm}^{-1}$ in spectra $\mathrm{b}$ and $\mathrm{c}$ does not coincide with the location of the respective band in bare oxalic acid dihydrate crystals $\left(1270 \mathrm{~cm}^{-1}\right)$. In spectrum c, a small doublet signature (highlighted by the circle) is apparent on the residual liquid water extinction band of the small number fraction of $\mathrm{NaCl} / \mathrm{OA} / \mathrm{H}_{2} \mathrm{O}$ solution droplets that have not yet crystallised. This feature might indicate the crystallisation of oxalic acid dihydrate, but, on the other hand, could also be explained by the formation of a small fraction of $\mathrm{NaCl} \cdot 2 \mathrm{H}_{2} \mathrm{O} / \mathrm{OA}$ particles already during the first crystallisation period, given that the hydration water in oxalic acid and sodium chloride dihydrate features a similar infrared spectral habitus. Concerning spectrum $\mathrm{b}$, any signature due to oxalic acid dihydrate in the $\mathrm{O}-\mathrm{H}$ stretching regime will be covered by the more intense features of $\mathrm{NaCl} \cdot 2 \mathrm{H}_{2} \mathrm{O}$. Therefore, we cannot conclude which species of oxalic acid has formed during crystallisation of the ternary $\mathrm{NaCl} / \mathrm{OA} / \mathrm{H}_{2} \mathrm{O}$ solution droplets.

\subsubsection{Results from the ternary $\mathrm{NaCl} / \mathrm{OA} / \mathrm{H}_{2} \mathrm{O}$ ice nucleation experiments 3,4 , and 5}

Having probed the heterogeneous ice nucleability of oxalic acid in a 0.51:5 mass ratio mixture with $\mathrm{NaCl}$, the experiments were repeated with two ternary solutions of lower OA content (Exps. 3 and 4). Figure 10 compares the respective AIDA records from the first expansion cooling cycles at $244 \mathrm{~K}$. The records for Exp. 3 (0.36:5 mass ratio of OA: $\mathrm{NaCl}$ ) closely reproduce the data from Exp. 2a (Fig. 5, right panel), i.e., the ice cloud is formed almost instantaneously as the seed aerosol particles are activated to micronsized cloud droplets at water saturation. In contrast, heterogeneous ice formation is almost absent in Exp. 4 (0.07:5 mass ratio of $\mathrm{OA}: \mathrm{NaCl}$ ) where only very few early ice crystals are detected by the OPC2. Instead, the droplet cloud glaciates at the homogeneous freezing temperature. In order to observe heterogeneous condensation mode ice nucleation by immersed OA particles at temperatures higher than

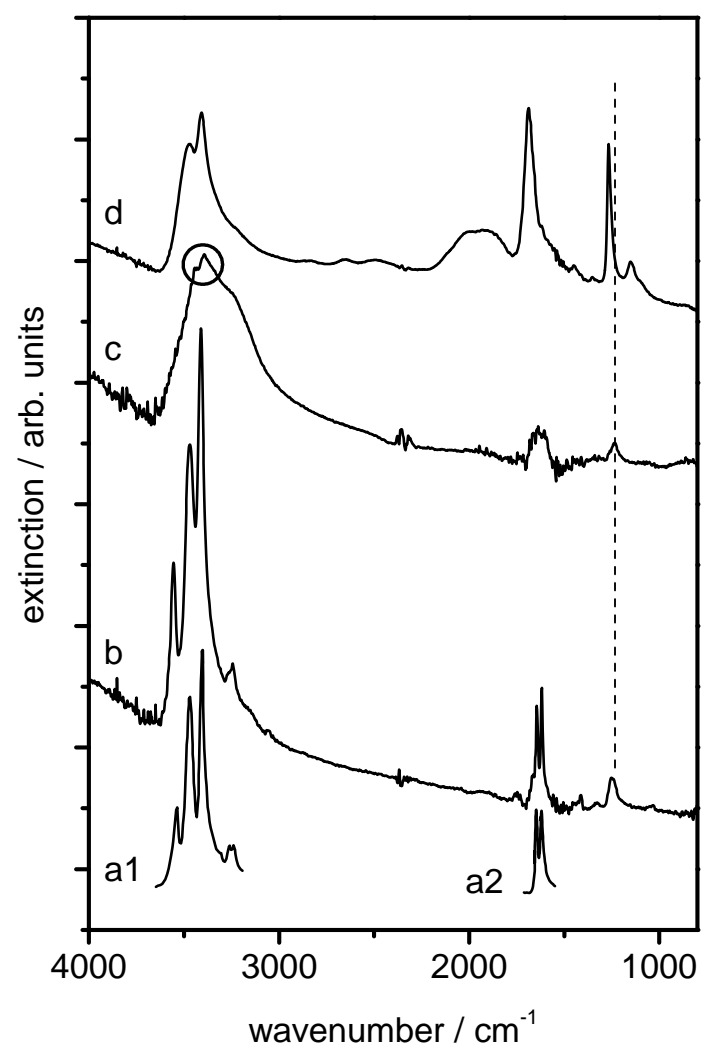

Fig. 9. Compilation of infrared spectra for various chemical species in the $\mathrm{NaCl} / \mathrm{OA} / \mathrm{H}_{2} \mathrm{O}$ system. Traces a1 and a2: Reference spectra of $\mathrm{NaCl} \cdot 2 \mathrm{H}_{2} \mathrm{O}$, obtained by digitising Fig. 1 from Schiffer and Hornig (1961). Trace b: Infrared extinction spectrum of effloresced $\mathrm{NaCl} \cdot 2 \mathrm{H}_{2} \mathrm{O} / \mathrm{OA}$ recorded after the second crystallisation period of Exp. 2b. Trace c: Infrared extinction spectrum of effloresced $\mathrm{NaCl} / \mathrm{OA}$ particles in an external mixture with a small fraction of unfrozen $\mathrm{NaCl} / \mathrm{OA} / \mathrm{H}_{2} \mathrm{O}$ solution droplets, recorded at the end of the first crystallisation period of Exp. 2a (lowermost spectrum from the series shown in the right panel in Fig. 4). Trace d: Infrared extinction spectrum of oxalic acid dihydrate crystals at $244 \mathrm{~K}$ from the study by Wagner et al. (2010). The dashed vertical line denotes the position of the $\mathrm{C}-\mathrm{O}$ stretching mode of oxalic acid at $1240 \mathrm{~cm}^{-1}$ in spectra $b$ and $c$. See text for details.

$237 \mathrm{~K}$, the size of the embedded particulates must evidently exceed a certain threshold size that will be defined by the dissolution kinetics of OA under the given experimental conditions. Treating the effloresced $\mathrm{NaCl} / \mathrm{OA}$ as spheres of diameter $0.7 \mu \mathrm{m}$ (see Fig. 3, left panel), the diameter of the immersed OA particles from Exp. 4 can be roughly estimated to about $0.17 \mu \mathrm{m}\left(\rho_{\mathrm{NaCl}}=2.17 \mathrm{~g} \mathrm{~cm}^{-3}, \rho_{\mathrm{OA}}=1.9 \mathrm{~g} \mathrm{~cm}^{-3}\right)$. These small embedded OA crystallites apparently get completely dissolved during droplet activation and, therefore, cannot trigger the early glaciation of the droplet cloud. A similar calculation for Exp. 3 where heterogeneous ice formation was observed yields a diameter for the OA inclusion of about $0.30 \mu \mathrm{m}$. During expansion cooling cycles started 

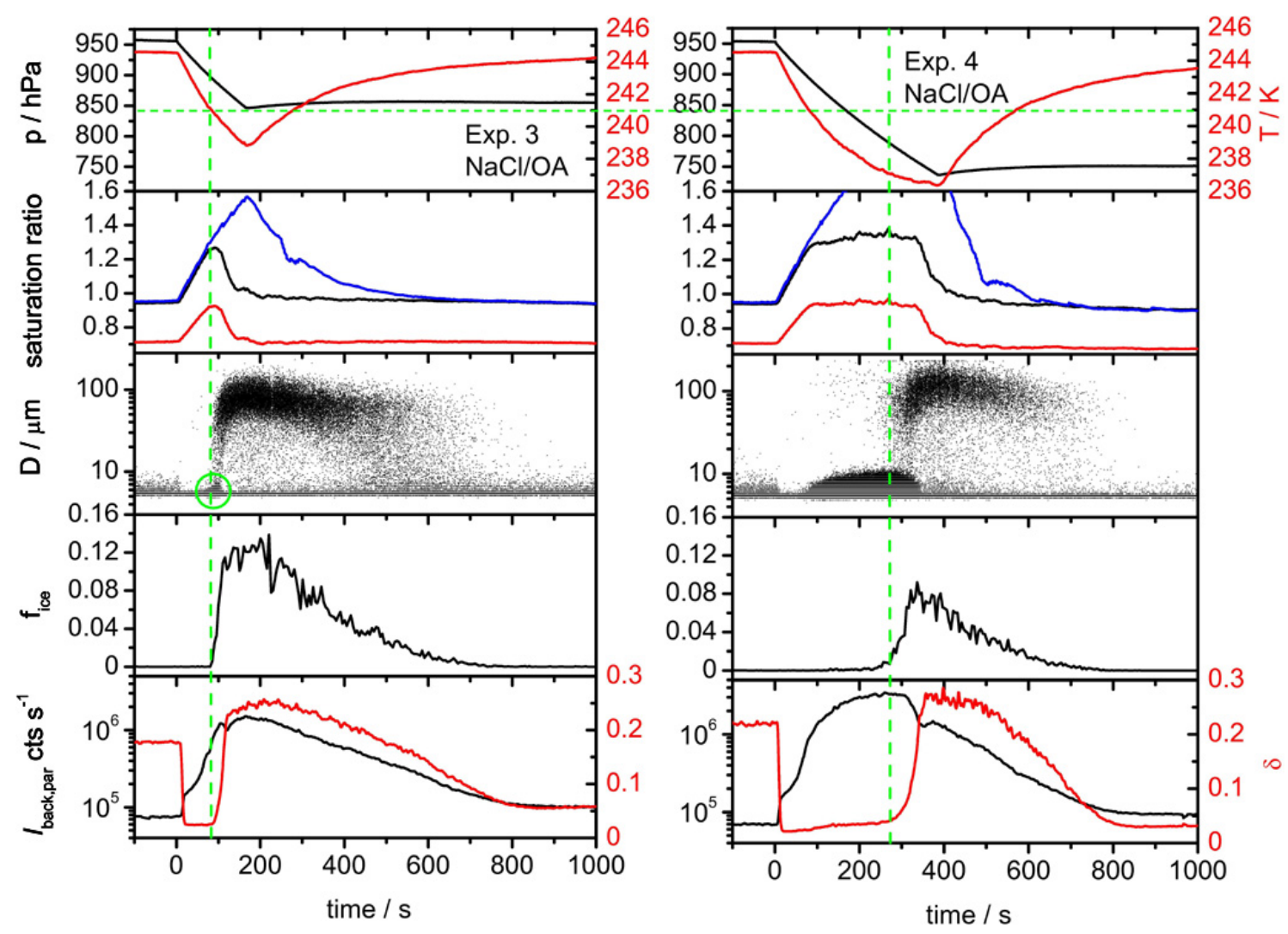

Fig. 10. Time series of various AIDA records during the first expansion cooling cycles from Exp. 3 (OA:NaCl mass ratio: 0.36:5) and Exp. 4 (OA: $\mathrm{NaCl}$ mass ratio: 0.07:5) that were started at $244 \mathrm{~K}$. The individual panels contain the same measurements as in Fig. 5.

at temperatures below $237 \mathrm{~K}$, however, the seed aerosol particles are not activated to almost pure water droplets and so even small OA inclusions will not dissolve and remain present as heterogeneous ice nuclei. This is evidenced by Fig. 11, showing the second expansion cooling cycles from Exp. 3 and Exp. 4 at $235 \mathrm{~K}$. In both experiments, heterogeneous ice nucleation by the embedded OA crystals can be detected, reducing the critical ice saturation $S_{\text {ice,crit }}$ from 1.38 (homogeneous freezing, see Exp. 1, denoted as horizontal green line in Fig. 11) to 1.31 (Exp. 3) and 1.33 (Exp. 4). As in Exp. 2a, the maximum ice saturation ratios encountered during the expansion runs remain below the homogeneous freezing threshold from the second expansion cooling cycle of Exp. 1. Note that the slight variations in $S_{\text {ice, crit }}$ between the various aerosol types is close to the absolute accuracy of the TDL measurements which, as stated in Sect. 3.1, is mainly due to the line strength uncertainty. In all expansion runs that are reported in Sect. 4.1, however, the same water vapour absorption line was scanned. Small relative variations in the critical ice saturation ratios therefore indeed point to a modified ice nucleation ability of the investigated particles.

The deliquescence transition during Exp. 3 features the well-known dual deliquescence behaviour due to the presence of both $\mathrm{NaCl} / \mathrm{OA}$ and $\mathrm{NaCl} \cdot 2 \mathrm{H}_{2} \mathrm{O} / \mathrm{OA}$ crystals. In con- trast, the deliquescence step due to $\mathrm{NaCl} \cdot 2 \mathrm{H}_{2} \mathrm{O}$ is almost absent in Exp. 4 since the major part of the aerosol population has already deliquesced at $72 \% \mathrm{RH}$. This behaviour can be well understood when considering that most $\mathrm{NaCl} / \mathrm{OA}$ crystals have completely deliquesced in the first expansion cooling cycle of Exp. 4. Homogeneous crystallisation will then again lead to the formation of anhydrous sodium chloride. In Exp. 3 the embedded OA crystals do not get completely dissolved during the first expansion cooling cycle and can initiate the heterogeneous crystallisation of sodium chloride dihydrate in the second crystallisation period. In the final experiment (Exp. 5), we have investigated whether a small addition of succinic acid to the ternary $\mathrm{NaCl} / \mathrm{OA} / \mathrm{H}_{2} \mathrm{O}$ solution from Exp. 3 will influence the heterogeneous ice nucleability of oxalic acid, recalling that Zobrist et al. (2006) have found that succinic acid was not ice-active in the immersion mode. During Exp. 5, only a single expansion cooling cycle at $244 \mathrm{~K}$ was performed whose records are depicted in Fig. 12. The AIDA records from Exp. 5 are almost duplicates of the respective data sets from Exp. 3 (left panel of Fig. 10), underlining that small admixtures of succinic acid do not suppress the high heterogeneous ice nucleability of oxalic acid. 

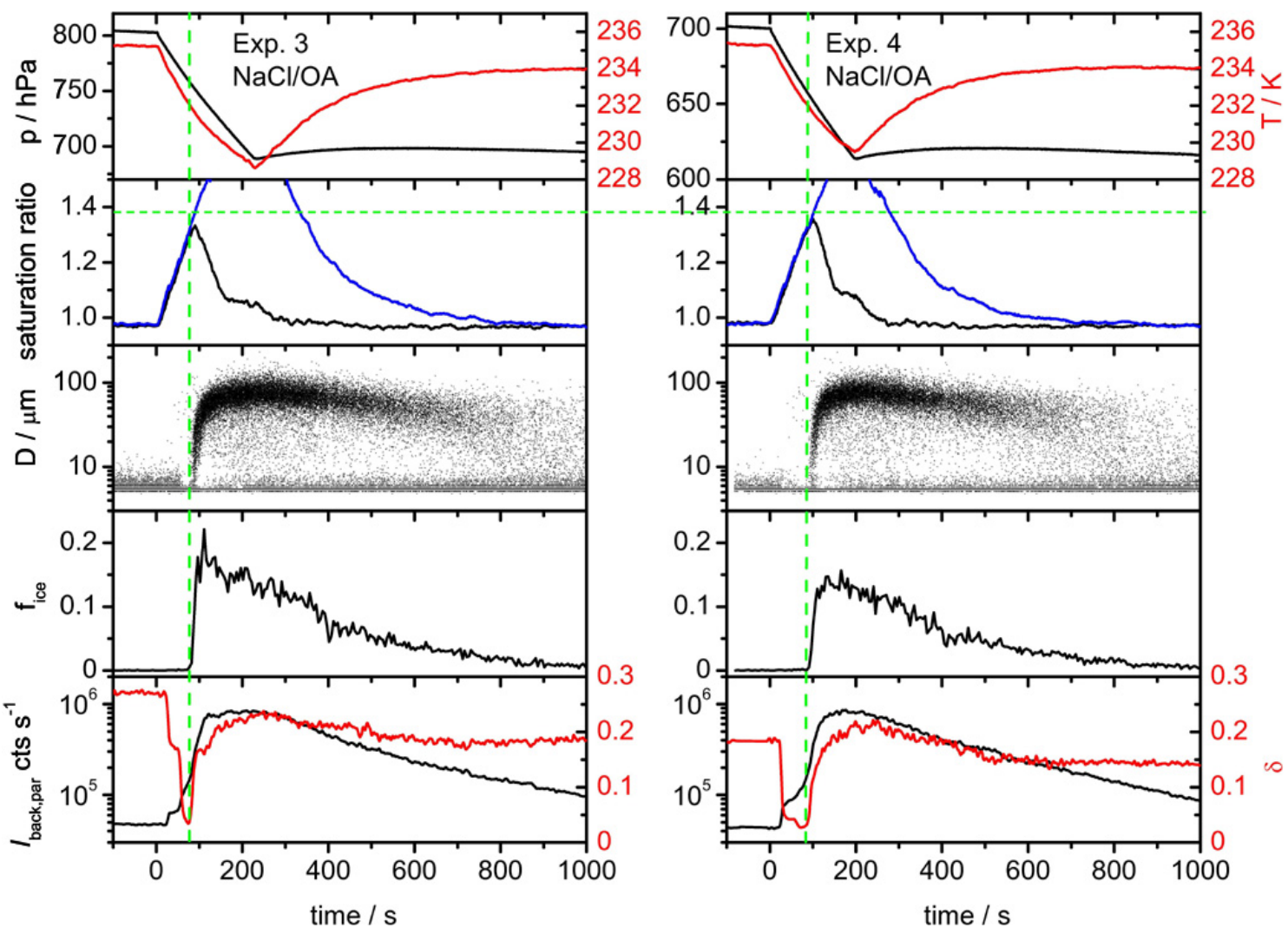

Fig. 11. Time series of various AIDA records during the second expansion cooling cycles from Exp. 3 and Exp. 4 that were started at 235 K. The individual panels contain the same measurements as in Fig. 7. The horizontal green line connecting the second row panels denotes the critical ice saturation ratio for homogeneous freezing of aqueous $\mathrm{NaCl}$ solution droplets, as detected in the second expansion cooling cycle of Exp. 1 (Fig. 7, left panel).

\subsubsection{Summary and comparison with literature data}

Table 2 summarises our findings on the hygroscopic and ice nucleation behaviour of the investigated $\mathrm{NaCl} / \mathrm{H}_{2} \mathrm{O}$, $\mathrm{NaCl} / \mathrm{OA} / \mathrm{H}_{2} \mathrm{O}$, and $\mathrm{NaCl} / \mathrm{OA} / \mathrm{SA} / \mathrm{H}_{2} \mathrm{O}$ aerosol particles. The data for the heterogeneous ice nucleation ability of immersed oxalic acid crystals in the condensation mode from the first expansion cooling cycles have their counterpart in emulsion freezing experiments within the binary oxalic $\mathrm{acid} / \mathrm{water}$ system from Zobrist et al. (2006). In the second cooling cycles with emulsified aqueous solutions of 4.95 , 9.76, and $19.87 \mathrm{wt} \%$ oxalic acid, the emulsions contained a solid oxalic acid dihydrate nucleus embedded in saturated oxalic acid solutions. Due to the small solubility of oxalic acid at low temperatures, the authors have chosen pure water as a reference for assessing the heterogeneous ice nucleability of oxalic acid. Compared to the homogeneous freezing temperature of pure water droplets, the freezing temperatures in presence of the heterogeneous ice nucleus were increased by 1.8 to $2.0 \mathrm{~K}$. In the AIDA expansion cooling experiments, this temperature difference was even $4 \mathrm{~K}$, as obtained by comparing the heterogeneous freezing temper- atures from experiments $2 \mathrm{a}, 2 \mathrm{~b}, 3$, and 5 with the homogeneous freezing temperature from experiments 1 and 4 . Our results on the immersion freezing potential of oxalic acid dihydrate from the second expansion cooling cycles can be compared to the findings from the emulsion experiments within the oxalic acid/aqueous solution systems shown in Table 2 of Zobrist et al. (2006). The authors have converted their measured heterogeneous freezing temperatures in the presence of precipitated oxalic acid (dihydrate) nano-crystals into a water-activity-based parameterisation, thereby constructing a heterogeneous freezing point line that is shifted by a small horizontal offset $\delta a_{\mathrm{w}}$ from the homogeneous freezing point line. By averaging over all measurements, $\delta a_{\mathrm{w}}$ was found to be 0.02 . In the AIDA chamber experiments, the difference in water activity between homogeneous and heterogeneous freezing runs is directly accessible via the TDL water vapour measurements. For example, the difference in $S_{\text {liq }}\left(a_{\mathrm{w}}\right)$ at the onset of ice nucleation between entirely liquid $\mathrm{NaCl}$ solution droplets from Exp. 1 that homogeneously froze at $231 \mathrm{~K}$ and $\mathrm{NaCl}$ solution droplets with embedded OA crystals from Exp. 2a that heterogeneously froze at $232 \mathrm{~K}$ was about 0.04 . This points towards an even higher 
Table 2. Overview of the hygroscopic and ice nucleation behaviour of the investigated aerosol particles in the systems $\mathrm{NaCl} / \mathrm{H}_{2} \mathrm{O}$, $\mathrm{NaCl} / \mathrm{OA} / \mathrm{H}_{2} \mathrm{O}$, and $\mathrm{NaCl} / \mathrm{OA} / \mathrm{SA} / \mathrm{H}_{2} \mathrm{O}$. For the first expansion runs that were started at $244 \mathrm{~K}$, the deliquescence relative humidity (DRH), the glaciation temperature $T_{\text {ice }}$ of the generated droplet cloud, and the ice-active number fraction of the aerosol population, $f_{\text {ice }}$, are given. For the second expansion runs that were started at $235 \mathrm{~K}$, the deliquescence relative humidity, the critical ice saturation ratio $S_{\text {ice,crit }}$ at the onset of ice nucleation, and $f_{\text {ice }}$ are given. Note that the second expansion run for Exp. $2 \mathrm{~b}$ was also performed at $244 \mathrm{~K}$, yielding a glaciation temperature of $241 \mathrm{~K}$ as in run 1 .

\begin{tabular}{|c|c|c|c|c|c|c|c|c|}
\hline Exp. & Solute(s) & $\begin{array}{r}\text { Mass ratio } \\
\text { solutes }\end{array}$ & $\begin{array}{r}1 \text { st run } \\
\text { DRH/\% }\end{array}$ & $\begin{array}{l}1 \text { st run } \\
T_{\text {ice }} / \mathrm{K}\end{array}$ & $\begin{array}{r}1 \text { st run } \\
f_{\text {ice }}\end{array}$ & $\begin{array}{l}\text { 2nd run } \\
\text { DRH/\% }\end{array}$ & $\begin{array}{c}2 \text { nd run } \\
S_{\text {ice,crit }}\end{array}$ & $\begin{array}{r}2 \text { nd run } \\
f_{\text {ice }}\end{array}$ \\
\hline 1 & $\mathrm{NaCl}$ & - & 72 & 237 & 0.15 & 72 & 1.38 & 0.20 \\
\hline $2 \mathrm{a}$ & $\mathrm{OA}, \mathrm{NaCl}$ & $0.51: 5$ & 72 & 241 & 0.11 & $72+82$ & 1.32 & 0.11 \\
\hline $2 b$ & $\mathrm{OA}, \mathrm{NaCl}$ & $0.51: 5$ & 72 & 241 & - & $72+82$ & - & - \\
\hline 3 & $\mathrm{OA}, \mathrm{NaCl}$ & $0.36: 5$ & 72 & 241 & 0.12 & $72+82$ & 1.31 & 0.18 \\
\hline 4 & $\mathrm{OA}, \mathrm{NaCl}$ & $0.07: 5$ & 72 & 237 & 0.08 & $72^{*}$ & 1.33 & 0.13 \\
\hline 5 & $\mathrm{SA}, \mathrm{OA}, \mathrm{NaCl}$ & $0.1: 0.36: 5$ & 72 & 241 & 0.15 & - & - & - \\
\hline
\end{tabular}

* As outlined in the discussion, only a very small second deliquescence step was observed at $82 \% \mathrm{RH}$.

heterogeneous ice nucleability of oxalic acid in the immersion mode compared to the Zobrist et al. (2006) results, in agreement with the higher heterogeneous freezing temperature that was already observed in the condensation mode ice nucleation experiments. $\delta a_{\mathrm{w}}$, however, can only be determined reliably from a larger number of measurements over a more extended temperature range.

The formation of immersed OA particulates in the supercooled $\mathrm{NaCl} / \mathrm{OA} / \mathrm{H}_{2} \mathrm{O}$ solution droplets was triggered by the crystallisation of the inorganic salt. Most presumably, in the atmosphere such solution droplets must be exposed to a lower relative humidity than prevalent in the AIDA vessel $(70 \% \mathrm{RH}$ at $244 \mathrm{~K})$ to induce the efflorescence transition because the outcome of the chamber experiments might be affected by heterogeneous crystallisation. Considering, however, our interpretation that the precipitation of $\mathrm{NaCl} \cdot 2 \mathrm{H}_{2} \mathrm{O}$ indicates heterogeneous crystallisation, as also emphasised by Koop et al. (2000), the absence of any $\mathrm{NaCl} \cdot 2 \mathrm{H}_{2} \mathrm{O}$ formation in the two crystallisation periods of pure $\mathrm{NaCl}$ solution droplets from Exp. 1 contradicts this hypothesis so that further measurements will be needed to clarify this issue.

Let us now briefly discuss the implication of our findings in the ternary $\mathrm{NaCl} / \mathrm{OA} / \mathrm{H}_{2} \mathrm{O}$ system for the envisaged experiments in the ternary $\mathrm{H}_{2} \mathrm{SO}_{4} / \mathrm{OA} / \mathrm{H}_{2} \mathrm{O}$ system. If solution droplets with immersed oxalic acid crystals are formed, our measurements indicate that at least a $10 \%$ number fraction of the aerosol population is ice-active, both in the expansion cooling cycles at 244 and $235 \mathrm{~K}$. In view of the experiments presented in Sect. 4.2, this means that at least $10 \mathrm{~cm}^{-3}$ sulphuric acid solution droplets with an immersed OA crystal must be formed in the first homogeneous freezing expansion run with the supercooled $\mathrm{H}_{2} \mathrm{SO}_{4} / \mathrm{OA} / \mathrm{H}_{2} \mathrm{O}$ solution droplets to yield an ice particle number concentration of about $1 \mathrm{~cm}^{-3}$ in the second expansion run due to heterogeneous ice nucleation which was identified as the threshold number concentration to clearly evidence this process. As outlined in the introduction, the number concentration of ice crystals formed by homogeneous freezing will be about $100 \mathrm{~cm}^{-3}$. Therefore, the precipitation of oxalic acid dihydrate from the $\mathrm{H}_{2} \mathrm{SO}_{4} / \mathrm{OA} / \mathrm{H}_{2} \mathrm{O}$ solutions must occur in every tenth ice crystal. In the following chapter, we describe whether this alternative pathway for the nucleation of oxalic acid dihydrate crystals, as previously evidenced in the emulsion freezing experiments by Zobrist et al. (2006), can also be observed in the AIDA expansion cooling experiments.

\subsection{Ice nucleation studies in the ternary $\mathrm{H}_{2} \mathrm{SO}_{4} / \mathrm{OA} / \mathrm{H}_{2} \mathrm{O}$ system}

This section comprises the analysis of the ice nucleation experiments 6-9 from Table 1 and is divided into three subsections. After a brief discussion of the reference ice nucleation experiment with binary $\mathrm{H}_{2} \mathrm{SO}_{4} / \mathrm{H}_{2} \mathrm{O}$ solution droplets in Sect. 4.2.1 (Exp. 6), the central Sect. 4.2.2 describes the results from repetitive expansion cooling cycles in the three ternary $\mathrm{H}_{2} \mathrm{SO}_{4} / \mathrm{OA} / \mathrm{H}_{2} \mathrm{O}$ experiments 7,8 , and 9 with varying OA solute concentration. An explanation to bring the reported findings into agreement with those from the Zobrist et al. (2006) emulsion freezing experiments is outlined in Sect. 4.2.3.

\subsubsection{Reference: ice nucleation study in the binary $\mathrm{H}_{2} \mathrm{SO}_{4} / \mathrm{H}_{2} \mathrm{O}$ system (Exp. 6)}

As in Sect. 4.1.1, we first briefly describe the results from reference expansion cooling experiments with binary $\mathrm{H}_{2} \mathrm{SO}_{4} / \mathrm{H}_{2} \mathrm{O}$ solution droplets at 244 and $235 \mathrm{~K}$ (Exp. 6, Fig. 13). The AIDA data shown in Fig. 13 in principle mimic those from the respective expansion cooling cycles in the binary $\mathrm{NaCl} / \mathrm{H}_{2} \mathrm{O}$ system (see left panels of Figs. 5 and 7), with the only exception that the $\mathrm{H}_{2} \mathrm{SO}_{4} / \mathrm{H}_{2} \mathrm{O}$ expansion runs were directly started with supercooled solution droplets so that the initial deliquescence step from crystalline $\mathrm{NaCl}$ particles to 


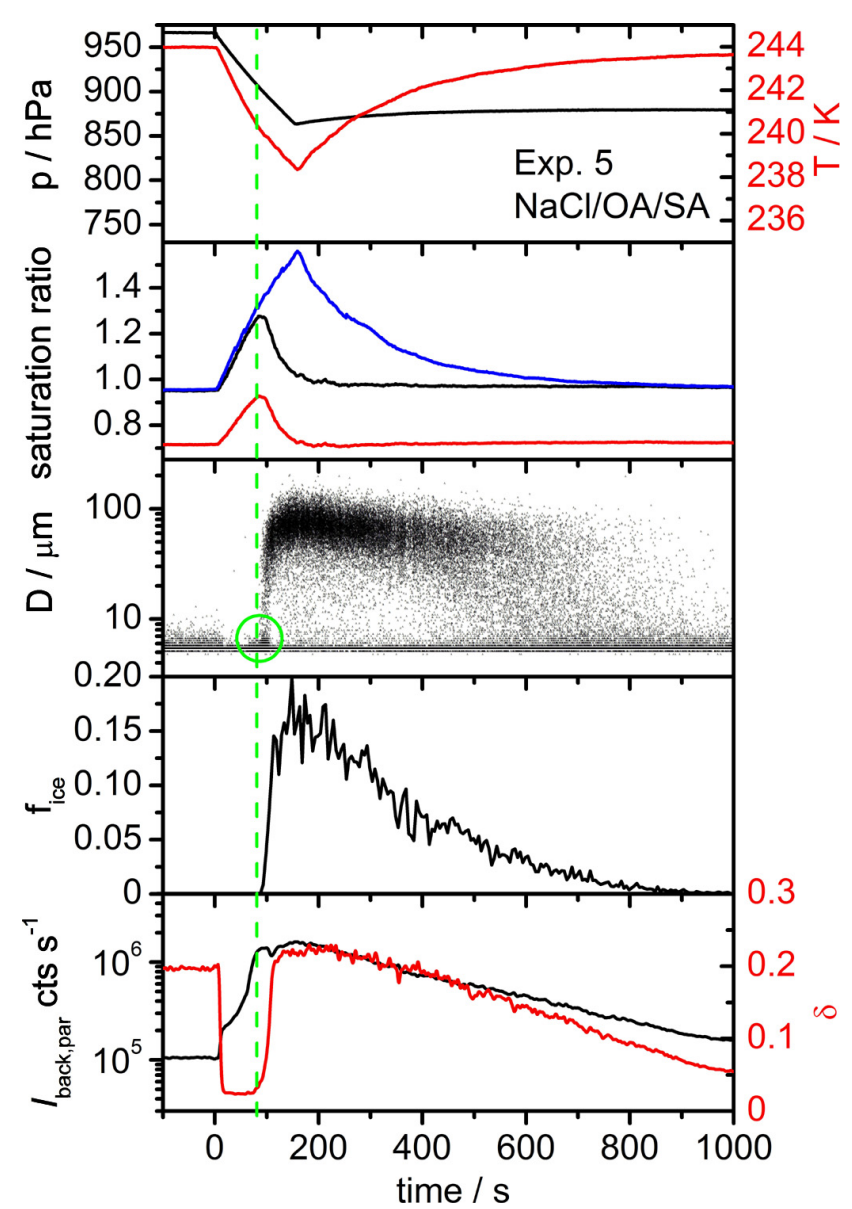

Fig. 12. Time series of various AIDA records during the expansion cooling cycle from Exp. 5 that was started at $244 \mathrm{~K}$. The individual panels contain the same measurements as in Fig. 5. The ice nucleation behaviour of the mixture of $\mathrm{NaCl}$, oxalic acid, and succinic acid is very much the same as that of the $\mathrm{NaCl}+$ oxalic acid mixture in Exp. 3 (left panel of Fig. 10).

aqueous sodium chloride solution droplets is missing. By contrast, the supercooled sulphuric acid solution droplets immediately adjust to the increasing relative humidity after the start of pumping at time zero by the uptake of water from the gas phase. The concomitant increase in particle size is evident by the increase in the intensity $I_{\text {back,par }}$ of the backscattered laser light. When starting the expansion run at $244 \mathrm{~K}$ (left panel), the $\mathrm{H}_{2} \mathrm{SO}_{4} / \mathrm{H}_{2} \mathrm{O}$ solution droplets are first activated to a droplet cloud when exceeding water saturation at $t=70 \mathrm{~s}$ (first vertical green line). The supercooled water droplets then homogeneously freeze at $t=230 \mathrm{~s}$ (second vertical green line) when the median gas temperature has dropped below $237 \mathrm{~K}$. In the expansion cooling experiment started at $235 \mathrm{~K}$ (right panel), the dilute sulphuric acid solution droplets homogeneously freeze at $S_{\text {ice }}=1.38(t=150 \mathrm{~s}$, vertical green line).

\subsubsection{Results from the ternary $\mathrm{H}_{2} \mathrm{SO}_{4} / \mathrm{OA} / \mathrm{H}_{2} \mathrm{O}$ ice nucleation experiments 7,8 , and 9}

The left and right panels of Fig. 14 show two repetitive expansion cooling runs with ternary $\mathrm{H}_{2} \mathrm{SO}_{4} / \mathrm{OA} / \mathrm{H}_{2} \mathrm{O}$ solution droplets having an oxalic acid to sulphuric acid mass ratio of 0.51:5 (Exp. 7). As outlined in Sect. 3.2, the aerosol particles were injected at $265 \mathrm{~K}$ and then cooled to $244 \mathrm{~K}$. In the first expansion run (left panel), about $60 \mathrm{~cm}^{-3}$ ice particles were generated by homogeneous freezing of the droplet cloud ( $t=220 \mathrm{~s}$, vertical green line) that had been formed in the early stage of the experiment upon exceeding water saturation. Only very few ice crystals $\left(N_{\text {ice }}<0.1 \mathrm{~cm}^{-3}\right)$ have nucleated before the homogeneous freezing threshold, indicating that the aerosol population has remained in a supercooled liquid state upon cooling, i.e., immersed oxalic acid (dihydrate) crystallites that could have acted as heterogeneous ice nuclei were not present. After the ice cloud from the first expansion run had evaporated, a second expansion run was started at $244 \mathrm{~K}$ to investigate whether the surface of the afore generated ice crystals had triggered the crystallisation of oxalic acid dihydrate from the unfrozen $\mathrm{H}_{2} \mathrm{SO}_{4} / \mathrm{OA} / \mathrm{H}_{2} \mathrm{O}$ solutions. Also in the second cooling cycle, however, ice formation was only observed after the droplet cloud had been cooled below the homogeneous freezing temperature of about $237 \mathrm{~K}$. Early heterogeneous freezing of at least a small fraction of the cloud droplets (those containing a solid oxalic acid dihydrate inclusion), as observed during experiments $2 \mathrm{a}$ and 3 in the $\mathrm{NaCl} / \mathrm{OA} / \mathrm{H}_{2} \mathrm{O}$ system (see right panel of Fig. 5 and left panel of Fig. 10), could not be detected. Subsequently, the AIDA chamber was cooled to $235 \mathrm{~K}$ to probe whether a change in the ice nucleation behaviour could be detected in two repetitive expansion cooling cycles with the same aerosol load at a lower temperature.

The left panel of Fig. 15 shows the AIDA records from the first expansion cooling experiment at $235 \mathrm{~K}$. The ternary $\mathrm{H}_{2} \mathrm{SO}_{4} / \mathrm{OA} / \mathrm{H}_{2} \mathrm{O}$ solution droplets homogeneously froze at $S_{\text {ice }}=1.38$ (vertical green line), yielding a peak ice particle number concentration of about $80 \mathrm{~cm}^{-3}$. The AIDA data from the second expansion cooling cycle that was started after the evaporation of the ice cloud from the preceding expansion is shown on an expanded time scale in the right panel. Whereas in the first expansion cooling cycle a fast pumping speed $\left(200 \mathrm{~m}^{3} \mathrm{~h}^{-1}\right)$ was used to produce a large number of ice crystals that could trigger the precipitation of oxalic acid dihydrate, the pumping speed and thus the humidification rate $d S_{\text {ice }} / d t$ was reduced in the second cooling cycle in order to be more sensitive for the detection of a small number concentration of ice crystals that potentially would be formed before the homogeneous freezing threshold. Given the results from the benchmark expansion cooling experiments with immersed OA crystals in the $\mathrm{NaCl} / \mathrm{OA} / \mathrm{H}_{2} \mathrm{O}$ system at $235 \mathrm{~K}$, the onset relative humidity due to immersion freezing would be at around $S_{\text {ice }}=1.32$ (see Table 2). This threshold is marked by the first vertical green line in the right 

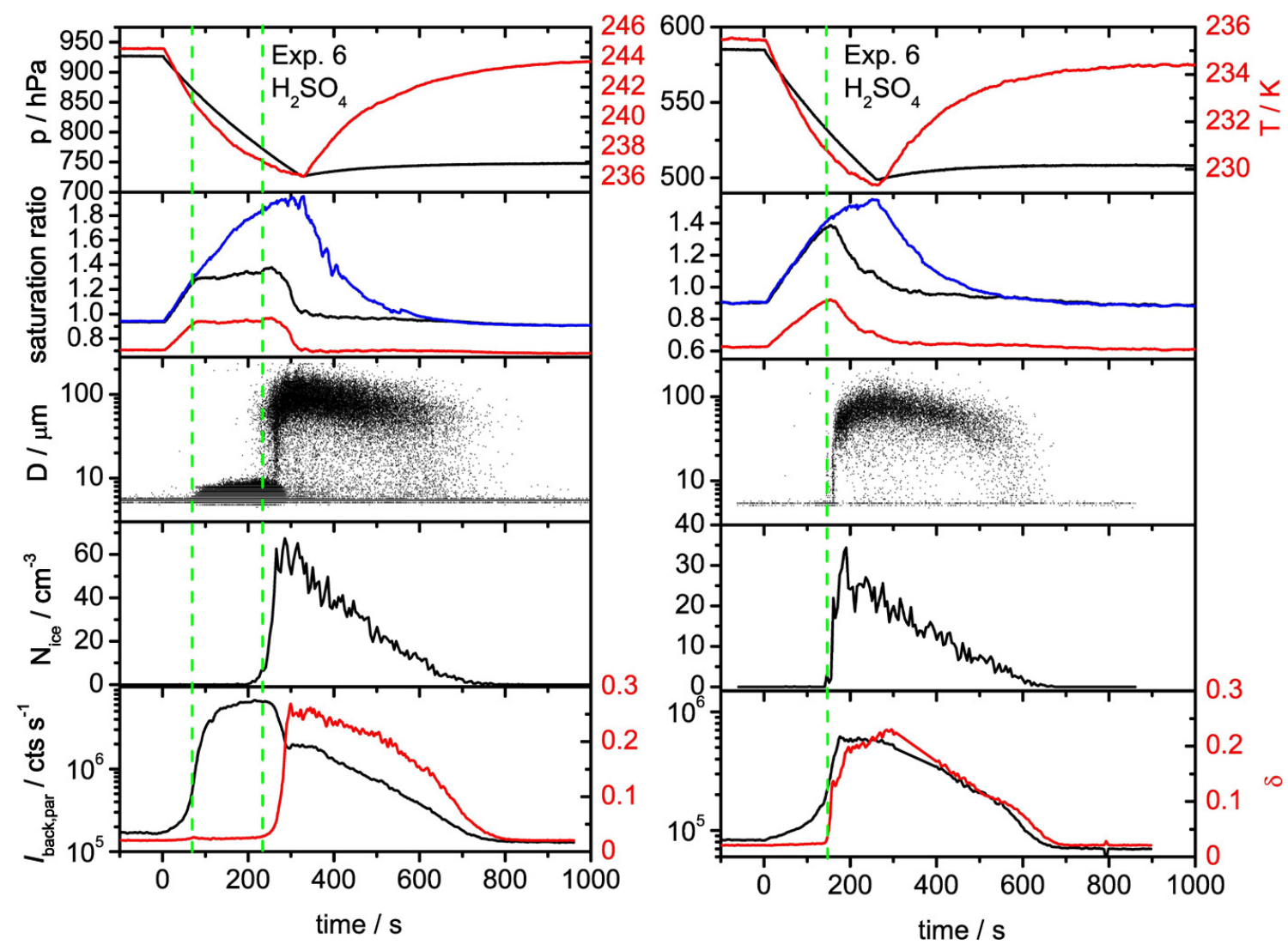

Fig. 13. Time series of various AIDA records during two expansion cooling cycles from Exp. 6 that were started at 244 and $235 \mathrm{~K}$. The individual panels show the same measurements as in Fig. 5, except from panel 4 where the ice particle number concentration $N_{\text {ice }}$ instead of the ice-active fraction $f_{\text {ice }}$ is shown.

panel of Fig. 15. As already outlined in Sect. 2.2, only a very small subset of the overall aerosol population is expected to be able to act as immersion freezing nucleus in the $\mathrm{H}_{2} \mathrm{SO}_{4} / \mathrm{OA} / \mathrm{H}_{2} \mathrm{O}$ system. Therefore, the number concentration of generated ice crystals will be too low to instantly deplete the water vapour supersaturation during the expansion so that soon after surpassing the heterogeneous freezing limit the homogeneous freezing threshold at $S_{\text {ice }}=1.38$ will be reached (second vertical green line in the right panel of Fig. 15). Only during a short time period of about $20 \mathrm{~s}$, whose duration can be adjusted by controlling the humidification rate, early heterogeneous ice nucleation by potentially precipitated oxalic acid dihydrate crystals can be expected. The AIDA records from Fig. 15 indicate that prior to the formation of the mode of homogeneously frozen solution droplets no early heterogeneous ice formation took place $\left(N_{\text {ice }} \leq 0.1 \mathrm{~cm}^{-3}\right)$. Given the difficulty to detect a small heterogeneous mode of ice crystals just prior to the homogeneous freezing mode at the lower temperature, the chamber was warmed again to $244 \mathrm{~K}$. At this temperature, it is easier to detect heterogeneous ice formation because the supercooled droplet cloud that is formed at water saturation persists for an elongated time period of up to $4 \mathrm{~min}$ before the gas temperatures has further dropped below the homogeneous freezing limit. But also in this expansion run (data not shown), early heterogeneous ice formation was not detected.

Besides the obvious conclusion that the efficiency of the ice surface mediated precipitation of oxalic acid (dihydrate) under the given experimental conditions was too low to become detectable, different explanations for the absence of heterogeneous ice formation should be considered. One cannot definitely exclude that a less ice-active species of solid oxalic acid has precipitated from the ternary $\mathrm{H}_{2} \mathrm{SO}_{4} / \mathrm{OA} / \mathrm{H}_{2} \mathrm{O}$ solution droplets compared to the experiments in the $\mathrm{NaCl} / \mathrm{OA} / \mathrm{H}_{2} \mathrm{O}$ system, given that oxalic acid is known to exist in various crystalline forms (Bellamy and Pace, 1963; Villepin and Novak, 1978a; Villepin and Novak, 1978b; Wenger and Bernstein, 2007) and that also the formation of solid amorphous particles has been recently discussed (Mikhailov et al., 2009). As outlined in Sect. 4.1, the chemical nature of (potentially) precipitated OA inclusions could not be identified. Given the observations from Exp. 2a with particles of the same OA solute concentration (Fig. 5, right panel and the related discussion), these embedded particulates would also be too small to change the value of the depolarisation ratio in relation to the background level 

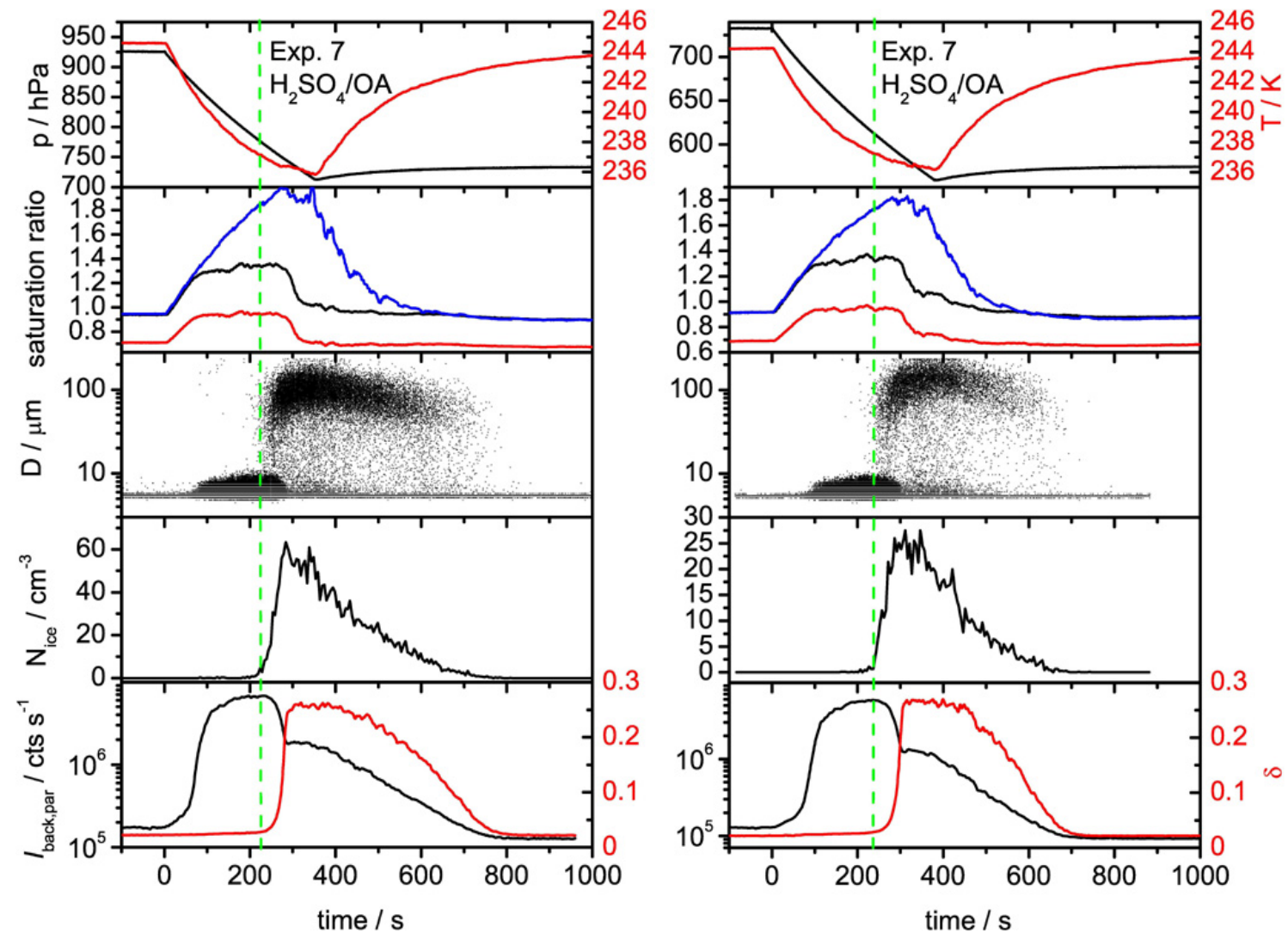

Fig. 14. Time series of various AIDA records during two consecutive expansion cooling cycles from Exp. 7 that were started at $244 \mathrm{~K}$. The individual panels show the same measurements as in Fig. 13.

of 0.02 and, therefore, their presence cannot be verified by this technique. One might also suggest that the OA inclusions were so small that they had instantly dissolved upon droplet activation during the expansion runs at $244 \mathrm{~K}$ (similar to Exp. 4, see right panel of Fig. 10) and that the heterogeneous and homogeneous freezing thresholds for the experiments started at $235 \mathrm{~K}$ were just too close to each other to observe early heterogeneous nucleation in a small subset of the overall aerosol population. As indicated in Sect. 3.2, the injection of the $\mathrm{H}_{2} \mathrm{SO}_{4} / \mathrm{OA} / \mathrm{H}_{2} \mathrm{O}$ solution droplets typically yielded very broad number size distributions centred at around $0.5 \mu \mathrm{m}$. For the first two expansion runs conducted at $244 \mathrm{~K}$ (Fig. 14), it is not feasible to assess what size fraction of the activated aerosol particles has nucleated ice in order to estimate the diameter of potentially precipitated OA inclusions. Such estimates, however, can be done for the final expansion run at $244 \mathrm{~K}$ that was performed after the two homogeneous freezing runs at $235 \mathrm{~K}$. As shown by modelling results on the homogeneous freezing of solution droplets in the AIDA chamber experiments, only solution droplets within a narrow range of the overall size distribution will freeze, i.e., the largest droplets that can still instantaneously react to the changing relative humidity during the expansion; see e.g. Fig. 8 in Haag et al. (2003). This regime of droplet sizes is typically centred at about $1 \mu \mathrm{m}$. Based on the AIM model, $1 \mu \mathrm{m}$-sized ternary $\mathrm{H}_{2} \mathrm{SO}_{4} / \mathrm{OA} / \mathrm{H}_{2} \mathrm{O}$ solution droplets with an OA: $\mathrm{H}_{2} \mathrm{SO}_{4}$ mass ratio of 0.51:5 (Exp. 7) have an oxalic acid content of $1.5 \mathrm{wt} \%$ at the threshold relative humidity for homogeneous freezing. With an estimated density $\rho$ of $1.15 \mathrm{~g} \mathrm{~cm}^{-3}$ for the dilute $\mathrm{H}_{2} \mathrm{SO}_{4} / \mathrm{OA} / \mathrm{H}_{2} \mathrm{O}$ solution droplets (approximated by the densities of binary $\mathrm{H}_{2} \mathrm{SO}_{4} / \mathrm{H}_{2} \mathrm{O}$ solutions from Luo et al., 1996), this would translate into a spherical OA inclusion with a diameter of about $0.2 \mu \mathrm{m}$ that might have precipitated from the ternary solution droplets. This size is only slightly larger than that estimated for the OA inclusions in Exp. 4 where early condensation mode ice nucleation has not been observed.

In a succeeding experiment within the $\mathrm{H}_{2} \mathrm{SO}_{4} / \mathrm{OA} / \mathrm{H}_{2} \mathrm{O}$ system, we have therefore more than doubled the OA solute concentration (Exp. 8, see Table 1). A solid OA inclusion, precipitated from a $1 \mu \mathrm{m}$-sized ternary solution droplet during a homogeneous freezing expansion cooling run at $235 \mathrm{~K}$, would now have a diameter of about $0.27 \mu \mathrm{m}$. This is close to the inclusion size estimated for Exp. 3 where early condensation mode ice nucleation by immersed OA particulates was clearly detected (left panel of Fig. 10). At first, we have again performed two repetitive expansion cooling runs at $244 \mathrm{~K}$. As in Exp. 7, the number concentration of ice crystals that 

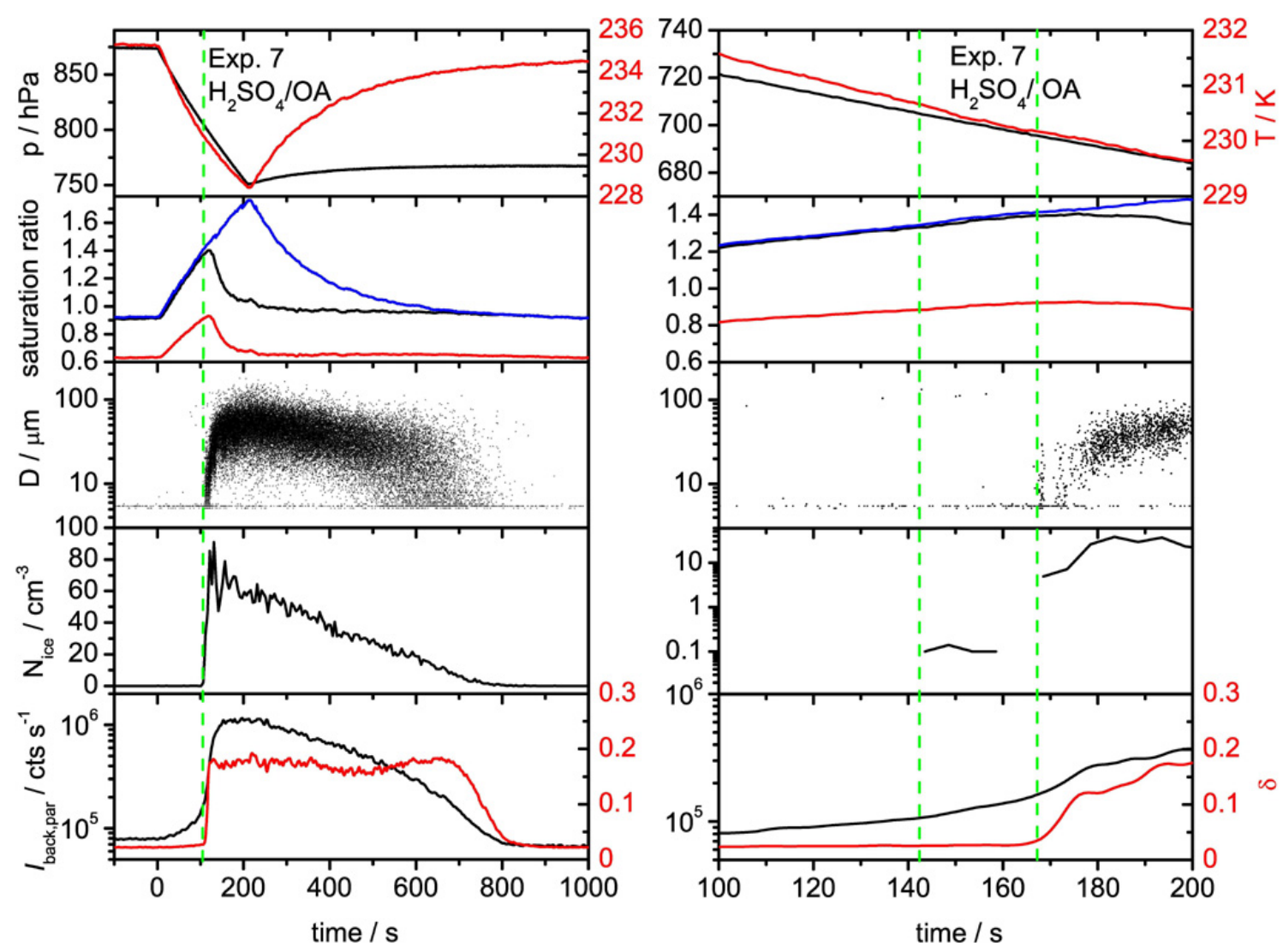

Fig. 15. Time series of various AIDA records during two consecutive expansion cooling cycles from Exp. 7 that were started at $235 \mathrm{~K}$. The individual panels show the same measurements as in Fig. 13. The y-axis scale in the fourth panel ( $\left.N_{\text {ice }}\right)$ of the second run was changed to logarithmic style in order to be more sensitive for small number concentrations of ice crystals that might have been formed by heterogeneous nucleation.

were formed by early heterogeneous nucleation in the second freezing run did not exceed the background level of 0.1-0.2 particles $\mathrm{cm}^{-3}$, i.e., was comparable to the ice crystal number concentration that has already been observed in the preceding expansion cooling run. We then changed the experimental procedure in comparison with Exp. 7 as follows. Instead of performing two repetitive expansion runs at $235 \mathrm{~K}$, the first one with a high cooling/humidification rate in order to generate a high number concentration of ice crystals by homogeneous freezing and the second one with a reduced humidification rate to detect early heterogeneous ice formation, we conducted a set of three fast expansion runs at $235 \mathrm{~K}$ in order to accumulate a detectable number of aerosol particles with solid oxalic acid inclusions that might have been formed in the individual homogeneous freezing experiments. In each of the three expansion runs at $235 \mathrm{~K}$, about $80-90 \mathrm{~cm}^{-3}$ ice crystals were formed by homogeneous freezing of the supercooled $\mathrm{H}_{2} \mathrm{SO}_{4} / \mathrm{OA} / \mathrm{H}_{2} \mathrm{O}$ solution droplets. In the second and third expansion run of the series, the ice clouds were forced to evaporate more rapidly in order to avoid the loss of some large ice crystals, together with their corresponding seed aerosol particles, by sedimentation. This was done by refilling the AIDA chamber with dry synthetic air shortly after the ice clouds had formed during the expansion runs. The aerosol vessel was then warmed to $244 \mathrm{~K}$ and another expansion cooling experiment was started to probe the ice nucleation behaviour of the aerosol processed by low temperature homogeneous freezing runs. Figure 16 compares the AIDA records from the expansion runs at $244 \mathrm{~K}$ before (left panel) and after (right panel) conducting the three fast homogeneous freezing runs at the lower temperature. As highlighted by the green circle in the OPC2 scatter plot of the right panel, a distinct early heterogeneous mode of ice crystals was formed by condensation mode ice nucleation immediately after the cloud of supercooled water droplets had been developed, similar to Exp. 2a (right panel of Fig. 5) and Exp. 3 (left panel of Fig. 10). The number concentration of ice crystals that were formed by heterogeneous nucleation is about $1 \mathrm{~cm}^{-3}$ and, thus, is clearly larger than the background level of ice particles that was observed prior to the expansion runs at $235 \mathrm{~K}$; see the horizontal green line connecting the $N_{\text {ice }}$ sub-panels in Fig. 16. Only because the supercooled droplet cloud persists for a sufficiently long period, the clear distinction between the small heterogeneous freezing mode 

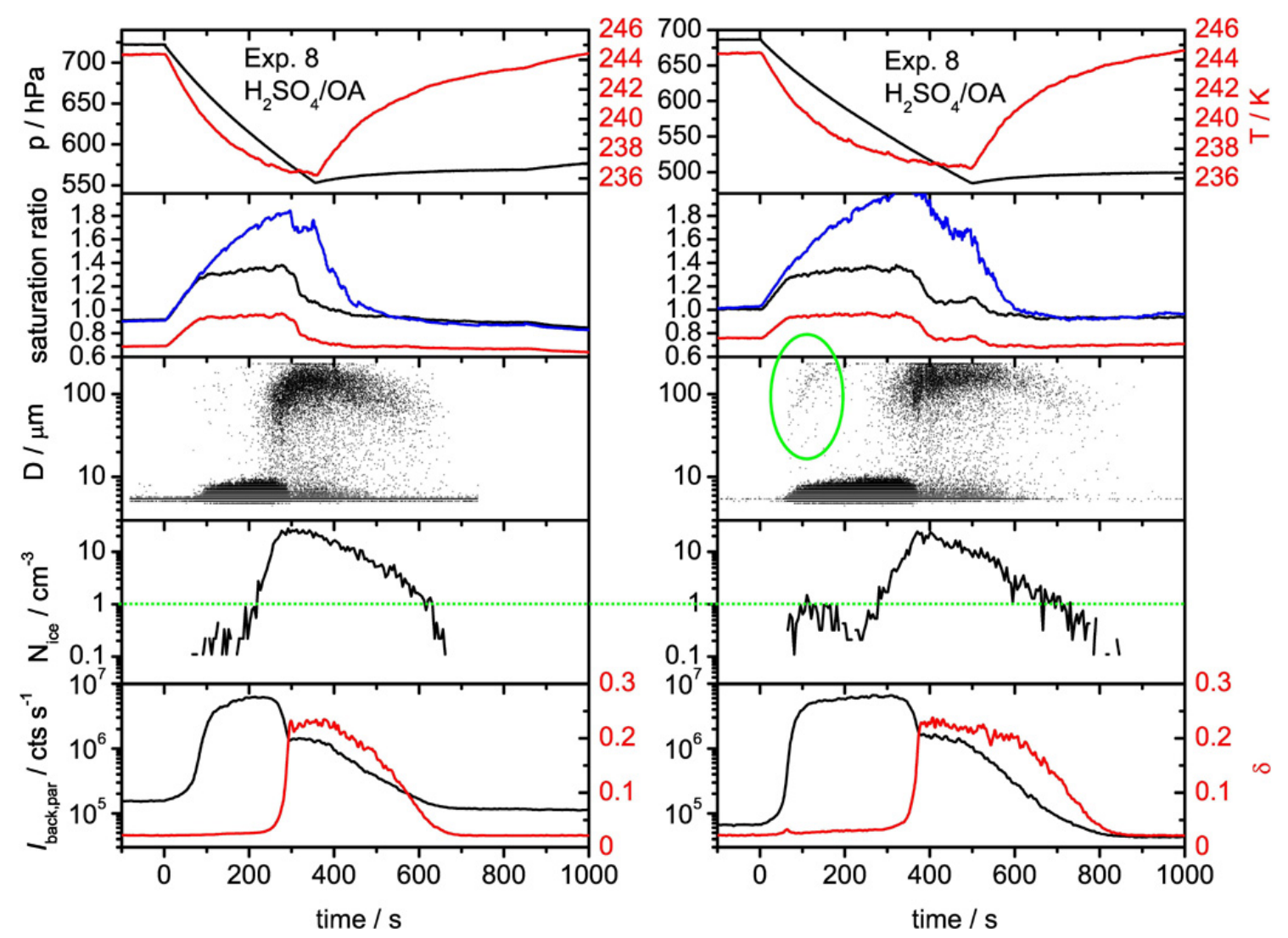

Fig. 16. Time series of various AIDA records during two expansion cooling cycles from Exp. 8 that were started at $244 \mathrm{~K}$. The individual panels show the same measurements as in Fig. 13.

and the still dominant homogeneous freezing mode is possible. Under the conditions of the AIDA ice nucleation experiments (air-borne particles, limited residence time of the generated ice clouds), the efficiency by which ice crystals with a surrounding or encapsulated $\mathrm{H}_{2} \mathrm{SO}_{4} / \mathrm{OA} / \mathrm{H}_{2} \mathrm{O}$ solution trigger the precipitation of an ice-active oxalic acid nucleus is therefore at most in the order of $1 \%$.

In the final experiment within the $\mathrm{H}_{2} \mathrm{SO}_{4} / \mathrm{OA} / \mathrm{H}_{2} \mathrm{O}$ system (Exp. 9), we have further increased the oxalic acid content in the ternary solution droplets, yielding an $\mathrm{OA}: \mathrm{H}_{2} \mathrm{SO}_{4}$ mass ratio of 3.43:5. This is similar to the $4: 4$ mass ratio that was employed in the corresponding emulsion freezing experiment by Zobrist et al. (2006); see Table 2 therein. The injected $\mathrm{H}_{2} \mathrm{SO}_{4} / \mathrm{OA} / \mathrm{H}_{2} \mathrm{O}$ solution droplets, however, did not remain in a supercooled liquid state upon cooling the AIDA chamber to $244 \mathrm{~K}$, as shown by the increase in the depolarisation ratio that was monitored after the gas temperature had dropped below about $252 \mathrm{~K}$ (black trace in the top panel of Fig. 17). According to the AIM model, the ternary solution droplets are composed of about $19 \mathrm{wt} \% \mathrm{H}_{2} \mathrm{SO}_{4}$ and $13 \mathrm{wt} \% \mathrm{OA}$ at $252 \mathrm{~K}$ under ice-saturated conditions (ice-coated chamber walls). Obviously, homogeneous crystallisation of oxalic acid (dihydrate) occurs for such elevated OA concentrations. The sizes of the OA inclusions are evidently large enough to pro- voke an increase in the depolarisation ratio and, furthermore, are large enough in order to not get instantly dissolved upon droplet activation during the expansion cooling run that was later on started at $244 \mathrm{~K}$ (lower part of Fig. 17). Upon formation of the droplet cloud at water saturation (as apparent by a denser point cloud in the OPC 2 scatter plot for particles $\leq 10 \mu \mathrm{m}$ and the temporary decrease in the depolarisation ratio, both marked by green circles in Fig. 17), the immersed OA particulates immediately trigger the glaciation of the droplet cloud at $T=241 \mathrm{~K}$ (vertical green line in Fig. 17), i.e., well above the homogeneous freezing temperature. This finding confirms the pronounced heterogeneous ice nucleability of immersed OA particulates that has already been observed in the $\mathrm{NaCl} / \mathrm{OA} / \mathrm{H}_{2} \mathrm{O}$ system.

\subsubsection{Conclusions}

In the introductory section, we have stated that the most plausible explanation for the precipitation of oxalic acid dihydrate in the first cooling cycles of the Zobrist et al. (2006) emulsion freezing experiments is heterogeneous crystallisation triggered by the surface of the homogeneously nucleated ice crystals. In view of the low efficiency of this mechanism in the AIDA ice nucleation experiments, we suggest 

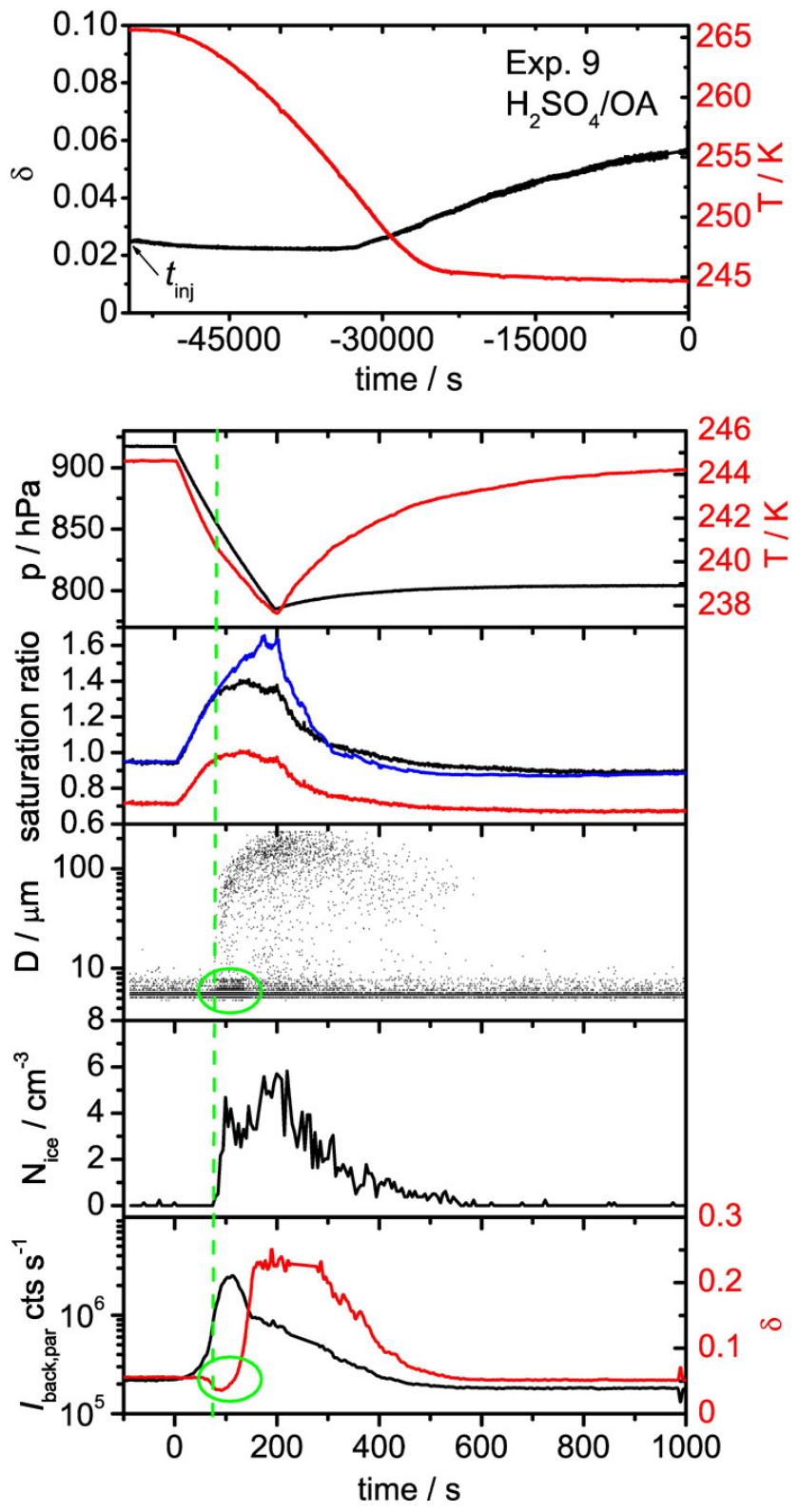

Fig. 17. Top part: Time series of the depolarisation ratio $\delta$ (black line) and the mean AIDA gas temperature (red line) after spraying ternary $\mathrm{H}_{2} \mathrm{SO}_{4} / \mathrm{OA} / \mathrm{H}_{2} \mathrm{O}$ solution droplets with an $\mathrm{OA}: \mathrm{H}_{2} \mathrm{SO}_{4}$ mass ratio of 3.43:5 (Exp. 9) into the aerosol vessel at $t=-55000 \mathrm{~s}$ $\left(t_{\text {inj }}\right)$. After aerosol addition, the chamber was cooled from 265 to $244 \mathrm{~K}$, see text for details. Bottom part: Time series of various AIDA records during the first expansion cooling cycle from Exp. 9 that was started at $244 \mathrm{~K}$. The individual panels show the same measurements as in Fig. 13.

that crystallisation in the emulsion experiments might also be the result of the increased oxalic acid concentration in the freeze concentrated solution that coexists with the ice crystals after homogeneous freezing. Once a dilute, emulsified aqueous oxalic acid solution is cooled below the homoge- neous freezing temperature in the first cooling cycle (e.g. below point B2 of trajectory $\mathrm{C}$ in Fig. 1), the solute concentration will follow the ice-melting point curve. The induced strong increase of the concentration of oxalic acid and of the supersaturation of oxalic acid dihydrate might increase the homogeneous crystallisation rate to such a degree to become detectable on the experimental time scale. This explanation would also account for the observations in the binary $\mathrm{OA} / \mathrm{H}_{2} \mathrm{O}$ system from our previous study (Wagner et al., 2010). As outlined in Sect. 1, we have always observed the crystallisation of oxalic acid dihydrate when adding dilute oxalic acid solution droplets into the AIDA chamber at temperatures $\leq 244 \mathrm{~K}$ under ice-saturated conditions (ice-coated chamber walls). Under such conditions, the injected solution droplets instantly attain a solute concentration of $>60 \mathrm{wt} \%$ oxalic acid; see Fig. 1 in Wagner et al. (2010). In the emulsion freezing experiments with binary oxalic acid/water solutions, such a high solute concentration is also obtained after ice has formed in the first homogeneous freezing runs. The impact of ice formation on the crystallisation of oxalic acid dihydrate might therefore solely be related to the increase in the solute concentration instead of providing a heterogeneous surface for the crystallisation. Concerning the experiments in the ternary $\mathrm{H}_{2} \mathrm{SO}_{4} / \mathrm{OA} / \mathrm{H}_{2} \mathrm{O}$ system, we have detected the homogeneous crystallisation of oxalic acid dihydrate in aqueous solution droplets prepared from a dilute $5 \mathrm{wt} \% \mathrm{H}_{2} \mathrm{SO}_{4}$ and $3.43 \mathrm{wt} \%$ OA solution (Exp. 9) when injected at $265 \mathrm{~K}$ and cooled to $244 \mathrm{~K}$ at ice-saturated conditions (Fig. 17, top part). As addressed in Sect. 3.2, the solution droplets will concentrate to about $24.0 \mathrm{wt} \% \mathrm{H}_{2} \mathrm{SO}_{4}$ and $16.5 \mathrm{wt} \%$ OA after cooling to $244 \mathrm{~K}$. Zobrist et al. (2006) have prepared a $4 \mathrm{wt} \% \mathrm{H}_{2} \mathrm{SO}_{4} / 4 \mathrm{wt} \%$ OA ternary solution for their freezing measurements in this system. After ice formation in the first cooling cycle, the unfrozen solution in the emulsion experiment will attain a similar composition as the ternary solution droplets in AIDA Exp. 9 before the expansion run at $244 \mathrm{~K}$ was started. Therefore, homogeneous crystallisation of oxalic acid dihydrate instead of ice-surface mediated heterogeneous crystallisation might have also occurred in the emulsion freezing experiments. In AIDA experiments 7 and 8 with a lower OA solute concentration, the oxalic acid dihydrate supersaturation and corresponding homogeneous crystallisation rate is obviously too low so that homogeneous crystallisation of oxalic acid dihydrate is not detectable at the time scale of the experiments. In contrast to the emulsion freezing experiments, the solute concentrations in AIDA expansion experiments are very similar at the start of the expansion runs (almost ice-saturated conditions) and shortly after ice formation when the ice supersaturation has again levelled off to an ice saturation ratio of one. Crystallisation of oxalic acid dihydrate can therefore only be induced heterogeneously by the surface of the nucleated ice crystals. The observed low efficiency of this process supports the assumption that the crystallisation of oxalic acid dihydrate in the emulsion freezing cycles might be due to homogeneous 
crystallisation of the freeze concentrated solutions. Zobrist et al. (2006) do not report additional freezing experiments in the ternary $\mathrm{H}_{2} \mathrm{SO}_{4} / \mathrm{OA} / \mathrm{H}_{2} \mathrm{O}$ system with a lower OA concentration to validate this hypothesis.

\section{Summary}

We have presented measurements on the heterogeneous ice nucleation ability of oxalic acid in the immersion mode by performing controlled expansion cooling cycles with airborne particles in the ternary $\mathrm{NaCl} / \mathrm{OA} / \mathrm{H}_{2} \mathrm{O}$ and $\mathrm{H}_{2} \mathrm{SO}_{4} / \mathrm{OA} / \mathrm{H}_{2} \mathrm{O}$ systems. The expansion runs were conducted in the AIDA aerosol and cloud chamber of the Karlsruhe Institute of Technology at initial temperatures of 244 and $235 \mathrm{~K}$. Immersed oxalic acid particulates were observed to reduce the critical ice saturation ratio, $S_{\text {ice, crit, }}$, required for the homogeneous freezing of aqueous solution droplets at a temperature of around $231 \mathrm{~K}$ from 1.38 to about 1.32 . Aqueous solution droplets with OA inclusions larger than about $0.27 \mu \mathrm{m}$ in diameter efficiently induced condensation mode ice nucleation when activated to cloud droplets at $241 \mathrm{~K}$, i.e., well above the homogeneous freezing temperature of pure water droplets of about $237 \mathrm{~K}$. The solid inclusions were presumably composed of oxalic acid dihydrate whose formation has been evidenced by infrared extinction spectroscopy in our preceding experiments on the crystallisation and ice nucleation behaviour of oxalic acid in the binary $\mathrm{OA} / \mathrm{H}_{2} \mathrm{O}$ system (Wagner et al., 2010).

The experiments in the ternary $\mathrm{H}_{2} \mathrm{SO}_{4} / \mathrm{OA} / \mathrm{H}_{2} \mathrm{O}$ system shed some light on the mechanism by which ice-active oxalic acid dihydrate crystals might nucleate in aqueous solution droplets. In supercooled sulphuric acid solution droplets with a high oxalic acid content of $13 \mathrm{wt} \%$, the homogeneous crystallisation of oxalic acid dihydrate was observed. Ternary solution droplets with a lower OA mass concentration that did not crystallise homogeneously on the experimental time scale were processed in a series of low-temperature homogeneous freezing runs to investigate whether the surface of the nucleated ice crystals would trigger the precipitation of oxalic acid dihydrate, a potential mechanism to explain the results from the emulsion freezing experiments by Zobrist et al. (2006). We have shown that the efficiency of this crystallisation pathway was very low under our experimental conditions. For ice cloud residence times of typically 10 15 min, only at most one out of a hundred ice crystals that had been generated in a homogeneous freezing expansion run has triggered the precipitation of an ice-active oxalic acid nucleus from the surrounding $\mathrm{H}_{2} \mathrm{SO}_{4} / \mathrm{OA} / \mathrm{H}_{2} \mathrm{O}$ solutions. This was evidenced by the appearance of a small, early heterogeneous mode of ice crystals prior to the homogeneous freezing threshold in a succeeding expansion cooling run. We therefore suggest that the crystallisation of oxalic acid dihydrate in the emulsion freezing experiments might just be related to the strong increase of the oxalic acid dihydrate supersat- uration upon ice formation, thereby enabling homogeneous crystallisation to become detectable on the time scale of the experiment. As an alternative pathway, mimicked by the experiments in the $\mathrm{NaCl} / \mathrm{OA} / \mathrm{H}_{2} \mathrm{O}$ system, oxalic acid dihydrate might also nucleate in a mixture of crystallisable inorganic salts when the relative humidity has dropped below the efflorescence point of the inorganic compound and the matrix of the inorganic particulates triggers its precipitation. As previously shown, oxalic acid dihydrate also readily crystallised from highly supersaturated binary oxalic water/water solution droplets at temperatures $\leq 244 \mathrm{~K}$ (Wagner et al., 2010).

Our new results underline that, in addition to the repeatedly observed high ice nucleation ability of bare oxalic acid dihydrate crystals in the deposition mode (Kanji et al., 2008; Wagner et al., 2010), also imbedded organic crystals enhance the ice nucleation ability of aqueous solution droplets. The AIDA experiments even disclose a slightly higher heterogeneous ice nucleation ability of immersed oxalic particles compared to the emulsion freezing runs conducted by Zobrist et al. (2006). For a closer inter-comparison of the ice nucleation results, however, it is important to cover a wider range of temperatures in future AIDA chamber studies to determine the horizontal shift $\delta a_{\mathrm{w}}$ from the homogeneous freezing point line. Zobrist et al. (2006) have used ECHAM4 climate model runs to assess the upper limit of the global net radiative effect due to heterogeneous ice nucleation by oxalic acid dihydrate. Such model runs are beyond the scope of our current manuscript. In the following, however, we want to compare the heterogeneous ice nucleation ability of oxalic acid dihydrate in the immersion mode with recent findings for other atmospherically relevant aerosol species like mineral dust and soot. Concerning the immersion freezing potential of mineral dust, Cziczo et al. (2009) have measured ice nucleation onset conditions for sulphuric acid and ammonium sulphate coated Arizona test dust (ATD) particles. Two experiments were performed at cirrus conditions (expansions 17 and 18 in Table 2, results plotted in Fig. 3 of their manuscript). Whereas freezing of ammonium sulphate coated ATD particles at $222.4 \mathrm{~K}$ required an ice saturation ratio approaching that for homogeneous ice nucleation, $S_{\text {ice,crit }}$ for the sulphuric acid coated ATD particles at $224.6 \mathrm{~K}$ was lowered by about 0.1 compared to the homogeneous freezing limit, i.e., a higher shift than observed in our oxalic acid experiments. On the contrary, Eastwood et al. (2009) report an onset relative humidity with respect to ice of about $133 \%$ at $233 \mathrm{~K}$ for ice nucleation on sulphuric acid coated kaolinite particles (taken from their Fig. 2) which is close to the freezing threshold observed for oxalic acid dihydrate crystals embedded in aqueous $\mathrm{NaCl}$ solution droplets (Sect. 4.1) Knopf and Koop (2006) have measured the ice nucleation on sulphuric acid coated ATD particles. For a comparison with our data, only those measurements where ice nucleation was measured on particles that were not preactivated should be considered (shown as solid circles in their Fig. 6). At $230 \mathrm{~K}$, the shift from the homogeneous freezing line for immersion 
freezing was close to that observed in the $\mathrm{NaCl} / \mathrm{OA} / \mathrm{H}_{2} \mathrm{O}$ system whereas at $220 \mathrm{~K}$ the onset relative humidity was considerably lower than that for homogeneous ice nucleation. Zobrist et al. (2008) have found $\delta a_{\mathrm{w}}$ to be 0.11 for emulsions with $5 \mathrm{wt} \%$ of immersed ATD particles, highlighting, however, that the magnitude of $\delta a_{\mathrm{w}}$ is highly variable and may be in the range from 0 to 0.157 , depending on the ATD loadings (Marcolli et al., 2007). Measurements by Archuleta et al. (2005) further emphasize that the magnitude of $\delta a_{\mathrm{w}}$ is also strongly size dependent, as shown e.g. in their Fig. 4 that summarises onset conditions for ice nucleation on 50, 100, and $200 \mathrm{~nm}$ sized silicate and metal oxide particles immersed in various aqueous solutions. On the one hand, this compilation underlines the high variability of the immersion freezing potential of dust particles but, on the other, also highlights that frequently much higher $\delta a_{\mathrm{w}}$ values were observed compared to the results for embedded oxalic acid dihydrate crystals from the Zobrist et al. (2006) study and our current work. Higher $\delta a_{\mathrm{w}}$ values were also observed for heterogeneous ice nucleation on sulphuric acid coated soot particles at temperatures between 230 and $185 \mathrm{~K}$ (Möhler et al., 2005). The implication of the heterogeneous ice nucleation ability of oxalic acid in the immersion mode for ice cloud formation on the local, regional, or even global scale therefore remains questionable and needs to be addressed in further modelling studies based on the data sets provided by Zobrist et al. (2006) and our current work.

Acknowledgements. The authors are grateful to all members of the AIDA staff for their continuous support during the numerous successful measurement campaigns on ice nucleation which have been conducted at the chamber facility in the past decade. We thank Julian Skrotzki and Volker Ebert for the data analysis of the TDL system. The work has been funded by the Helmholtz-Gemeinschaft deutscher Forschungszentren as part of the program "Atmosphere and Climate".

Edited by: D. Knopf

\section{References}

Archuleta, C. M., DeMott, P. J., and Kreidenweis, S. M.: Ice nucleation by surrogates for atmospheric mineral dust and mineral dust/sulfate particles at cirrus temperatures, Atmos. Chem. Phys., 5, 2617-2634, doi:10.5194/acp-5-2617-2005, 2005.

Arnott, W. P., Dong, Y. Y., and Hallett, J.: Extinction Efficiency in the Infrared $(2-18 \mu \mathrm{m})$ of Laboratory Ice Clouds - Observations of Scattering Minima in the Christiansen Bands of Ice, Appl. Optics, 34, 541-551, 1995.

Bellamy, L. J. and Pace, R. J.: Hydrogen Bonding in Carboxylic Acids.1. Oxalic Acids, Spectrochim. Acta, 19, 435-442, 1963.

Benz, S., Megahed, K., Möhler, O., Saathoff, H., Wagner, R., and Schurath, U.: T-dependent rate measurements of homogeneous ice nucleation in cloud droplets using a large atmospheric simulation chamber, J. Photochem. Photobiol. A, 176, 208-217, 2005.
Braban, C. F., Carroll, M. F., Styler, S. A., and Abbatt, J. P. D.: Phase transitions of malonic and oxalic acid aerosols, J. Phys. Chem. A, 107, 6594-6602, 2003.

Brooks, S. D., Wise, M. E., Cushing, M., and Tolbert, M. A.: Deliquescence behavior of organic/ammonium sulfate aerosol, Geophys. Res. Lett., 29, 1917-1920, 2002.

Choi, M. Y. and Chan, C. K.: The effects of organic species on the hygroscopic behaviors of inorganic aerosols, Environ. Sci. Technol., 36, 2422-2428, 2002.

Clegg, S. L. and Seinfeld, J. H.: Thermodynamic models of aqueous solutions containing inorganic electrolytes and dicarboxylic acids at $298.15 \mathrm{~K}$. 1 . The acids as nondissociating components, J. Phys. Chem. A, 110, 5692-5717, 2006a.

Clegg, S. L. and Seinfeld, J. H.: Thermodynamic models of aqueous solutions containing inorganic electrolytes and dicarboxylic acids at 298.15 K. 2. Systems including dissociation equilibria, J. Phys. Chem. A, 110, 5718-5734, 2006b.

Clegg, S. L., Brimblecombe, P., and Wexler, A. S.: Thermodynamic model of the system $\mathrm{H}^{+}-\mathrm{NH}_{4}^{+}-\mathrm{SO}_{4}^{2-}-\mathrm{NO}_{3}^{-}-\mathrm{H}_{2} \mathrm{O}$ at tropospheric temperatures, J. Phys. Chem. A, 102, 2137-2154, http://www. aim.env.uea.ac.uk/aim/aim.php, 1998.

Cziczo, D. J. and Abbatt, J. P. D.: Infrared observations of the response of $\mathrm{NaCl}, \mathrm{MgCl}_{2}, \mathrm{NH}_{4} \mathrm{HSO}_{4}$, and $\mathrm{NH}_{4} \mathrm{NO}_{3}$ aerosols to changes in relative humidity from 298 to $238 \mathrm{~K}$, J. Phys. Chem. A, 104, 2038-2047, 2000.

Cziczo, D. J., Froyd, K. D., Gallavardin, S. J., Möhler, O., Benz, S., Saathoff, H., and Murphy, D. M.: Deactivation of ice nuclei due to atmospherically relevant surface coatings, Environ. Res. Letters, 4, 044013, doi:10.1088/1748-9326/4/4/044013, 2009.

Eastwood, M. L., Cremel, S., Wheeler, M., Murray, B. J., Girard, E., and Bertram, A. K.: Effects of sulfuric acid and ammonium sulfate coatings on the ice nucleation properties of kaolinite particles, Geophys. Res. Lett., 36, L02811, doi:10.1029/2008GL035997, 2009.

Gao, Y. G., Chen, S. B., and Yu, L. E.: Efflorescence relative humidity of airborne sodium chloride particles: A theoretical investigation, Atmos. Environ., 41, 2019-2023, 2007.

Haag, W., Kärcher, B., Schaefers, S., Stetzer, O., Möhler, O., Schurath, U., Krämer, M., and Schiller, C.: Numerical simulations of homogeneous freezing processes in the aerosol chamber AIDA, Atmos. Chem. Phys., 3, 195-210, doi:10.5194/acp-3-195-2003, 2003.

Herz, W. and Neukirch, E.: Die Beeinflussung der Oxalsäurelöslichkeit durch starke Säuren, Z. Anorg. Allg. Chem., 131, 303-309, 1923.

Kanji, Z. A., Florea, O., and Abbatt, J. P. D.: Ice formation via deposition nucleation on mineral dust and organics: dependence of onset relative humidity on total particulate surface area, Environ. Res. Lett., 3, 025004, doi:10.1088/1748-9326/3/2/025004, 2008.

Kawamura, K., Kasukabe, H., and Barrie, L. A.: Source and reaction pathways of dicarboxylic acids, ketoacids and dicarbonyls in arctic aerosols: One year of observations, Atmos. Environ., 30, 1709-1722, 1996.

Kerminen, V. M., Teinila, K., Hillamo, R., and Makela, T.: Sizesegregated chemistry of particulate dicarboxylic acids in the Arctic atmosphere, Atmos. Environ., 33, 2089-2100, 1999.

Kerminen, V. M., Ojanen, C., Pakkanen, T., Hillamo, R., Aurela, M., and Merilainen, J.: Low-molecular-weight dicarboxylic acids in an urban and rural atmosphere, J. Aerosol Sci., 31, 349- 
$362,2000$.

Knopf, D. A. and Koop, T.: Heterogeneous nucleation of ice on surrogates of mineral dust, J. Geophys. Res. Atmos., 111, D12201, doi:10.1029/2005JD006894, 2006.

Koop, T., Kapilashrami, A., Molina, L. T., and Molina, M. J.: Phase transitions of sea-salt/water mixtures at low temperatures: Implications for ozone chemistry in the polar marine boundary layer, J. Geophys. Res. Atmos., 105, 26393-26402, 2000.

Lightstone, J. M., Onasch, T. B., Imre, D., and Oatis, S.: Deliquescence, efflorescence, and water activity in ammonium nitrate and mixed ammonium nitrate/succinic acid microparticles, J. Phys. Chem. A, 104, 9337-9346, 2000.

Liu, L., Mishchenko, M. I., Cairns, B., Carlson, B. E., and Travis, L. D.: Modeling single-scattering properties of small cirrus particles by use of a size-shape distribution of ice spheroids and cylinders, J. Quant. Spectrosc. Ra., 101, 488-497, 2006.

Luo, B., Krieger, U. K., and Peter, T.: Densities and refractive indices of $\mathrm{H}_{2} \mathrm{SO}_{4} / \mathrm{HNO}_{3} / \mathrm{H}_{2} \mathrm{O}$ solutions to stratospheric temperatures, Geophys. Res. Lett., 23, 3707-3710, 1996.

Marcolli, C., Luo, B. P., and Peter, T.: Mixing of the organic aerosol fractions: Liquids as the thermodynamically stable phases, J. Phys. Chem. A, 108, 2216-2224, 2004.

Marcolli, C., Gedamke, S., Peter, T., and Zobrist, B.: Efficiency of immersion mode ice nucleation on surrogates of mineral dust, Atmos. Chem. Phys., 7, 5081-5091, doi:10.5194/acp-7-50812007, 2007.

Mikhailov, E., Vlasenko, S., Martin, S. T., Koop, T., and Pöschl, U.: Amorphous and crystalline aerosol particles interacting with water vapor: conceptual framework and experimental evidence for restructuring, phase transitions and kinetic limitations, Atmos. Chem. Phys., 9, 9491-9522, doi:10.5194/acp-9-9491-2009, 2009.

Mishchenko, M. I., Travis, L. D., and Mackowski, D. W.: T-matrix computations of light scattering by nonspherical particles: A review, J. Quant. Spectrosc. Ra., 55, 535-575, 1996.

Möhler, O., Büttner, S., Linke, C., Schnaiter, M., Saathoff, H., Stetzer, O., Wagner, R., Krämer, M., Mangold, A., Ebert, V., and Schurath, U.: Effect of Sulphuric Acid Coating on Heterogeneous Ice Nucleation by Soot Aerosol Particles, J. Geophys. Res. Atmos., 110, D11210, doi:10.1029/2004JD005169, 2005.

Möhler, O., Georgakopoulos, D. G., Morris, C. E., Benz, S., Ebert, V., Hunsmann, S., Saathoff, H., Schnaiter, M., and Wagner, R.: Heterogeneous ice nucleation activity of bacteria: new laboratory experiments at simulated cloud conditions, Biogeosciences, 5, 1425-1435, doi:10.5194/bg-5-1425-2008, 2008.

Murphy, D. M. and Koop, T.: Review of the vapour pressures of ice and supercooled water for atmospheric applications, Q. J. R. Meteorol. Soc., 131, 1539-1565, 2005.

Parsons, M. T., Mak, J., Lipetz, S. R., and Bertram, A. K.: Deliquescence of malonic, succinic, glutaric, and adipic acid particles, J. Geophys. Res. (Atmos.), 109, D06212, doi:10.1029/2003JD004075, 2004.

Prenni, A. J., DeMott, P. J., Kreidenweis, S. M., Sherman, D. E., Russell, L. M., and Ming, Y.: The effects of low molecular weight dicarboxylic acids on cloud formation, J. Phys. Chem. A, 105, 11240-11248, 2001.

Pruppacher, H. R. and Klett, J. D.: Microphysics of Clouds and Precipitation, Kluwer Acacdemic Publishers, Dordrecht, 1997.

Schiffer, J. and Hornig, D. F.: On a Reported New Form of Ice, J.
Chem. Phys., 35, 1136-1137, 1961.

Treuel, L., Schulze, S., Leisner, T., and Zellner, R.: Deliquescence behaviour of single levitated ternary salt/carboxylic acid/water microdroplets, Faraday Discuss., 137, 265-278, 2008.

Villepin, J. D. and Novak, A.: Vibration-Spectra of Oxalic Acids.1. Infrared and Raman-Spectra of Beta-Phase of Some Acids, Spectrochim. Acta A, 34, 1009-1017, 1978a.

Villepin, J. D. and Novak, A.: Vibration-Spectra of Oxalic Acids.2. Infrared and Raman-Spectra of Alpha-Phase of Some Acids, Spectrochim. Acta A, 34, 1019-1024, 1978b.

Wagner, R., Benz, S., Möhler, O., Saathoff, H., and Schurath, U.: Probing ice clouds by broadband mid-infrared extinction spectroscopy: case studies from ice nucleation experiments in the AIDA aerosol and cloud chamber, Atmos. Chem. Phys., 6, 47754800, doi:10.5194/acp-6-4775-2006, 2006a.

Wagner, R., Bunz, H., Linke, C., Möhler, O., Naumann, K. H., Saathoff, H., Schnaiter, M., and Schurath, U.: Chamber Simulations of Cloud Chemistry: The AIDA Chamber, in Proceedings of the NATO Advances Research Workshop on Environmental Simulation Chambers: Application to Atmospheric Chemical Processes, held in Zakopane, Poland, from 1 to 4 October 2004, edited by: Barnes, I. and Rudzinski, K. J., Springer, 2006b.

Wagner, R., Benz, S., Bunz, H., Möhler, O., Saathoff, H., Schnaiter, M., Leisner, T., and Ebert, V.: Infrared Optical Constants of Highly Diluted Sulfuric Acid Solution Droplets at Cirrus Temperatures, J. Phys. Chem. A, 112, 11661-11676, 2008.

Wagner, R., Linke, C., Naumann, K. H., Schnaiter, M., Vragel, M., Gangl, M., and Horvath, H.: A review of optical measurements at the aerosol and cloud chamber AIDA, J. Quant. Spectrosc. Ra., 110, 930-949, 2009.

Wagner, R., Möhler, O., Saathoff, H., Schnaiter, M., and Leisner, T.: High variability of the heterogeneous ice nucleation potential of oxalic acid dihydrate and sodium oxalate, Atmos. Chem. Phys., 10, 7617-7641, doi:10.5194/acp-10-7617-2010, 2010.

Wenger, M. and Bernstein, J.: Cocrystal design gone awry?, A new dimorphic hydrate of oxalic acid, Mol. Pharm., 4, 355-359, 2007.

Wexler, A. S.,and Seinfeld, J. H.: Second-Generation Inorganic Aerosol Model, Atmos. Environ., 25A, 2731-2748, 1991.

Zakharova, N. T. and Mishchenko, M. I.: Scattering properties of needlelike and platelike ice spheroids with moderate size parameters, Appl. Optics, 39, 5052-5057, 2000.

Zasetsky, A. Y., Khalizov, A. F., Earle, M. E., and Sloan, J. J.: Frequency Dependent Complex Refractive Indices of Supercooled Liquid Water and Ice Determined from Aerosol Extinction Spectra, J. Phys. Chem. A, 109, 2760-2764, 2005.

Zobrist, B., Marcolli, C., Koop, T., Luo, B. P., Murphy, D. M., Lohmann, U., Zardini, A. A., Krieger, U. K., Corti, T., Cziczo, D. J., Fueglistaler, S., Hudson, P. K., Thomson, D. S., and Peter, T.: Oxalic acid as a heterogeneous ice nucleus in the upper troposphere and its indirect aerosol effect, Atmos. Chem. Phys., 6, 3115-3129, doi:10.5194/acp-6-3115-2006, 2006.

Zobrist, B., Marcolli, C., Peter, T., and Koop, T.: Heterogeneous ice nucleation in aqueous solutions: the role of water activity, J. Phys. Chem. A, 112, 3965-3975, 2008.

Zuberi, B., Bertram, A. K., Koop, T., Molina, L. T., and Molina, M. J.: Heterogeneous freezing of aqueous particles induced by crystallized $\left(\mathrm{NH}_{4}\right)_{2} \mathrm{SO}_{4}$, ice, and letovicite, J. Phys. Chem. A, 105, 6458-6464, 2001. 